\title{
La fotografía aérea en México para el estudio de la ciudad: el crucero de El Caballito
}

\begin{abstract}
Lourdes Roca ${ }^{1}$
RESUMEN: El texto plantea algunas posibilidades de investigación con fotografías aéreas, centrándose en el estudio de la ciudad. Ubicado en el caso mexicano, esboza un panorama de la fotografía aérea en México, para enseguida revisar el potencial de este tipo de registro como fuente de investigación. El corpus visual analizado está constituido por una treintena de imágenes aéreas que van de 1932 a 1978 y capturan el espacio urbano que se construye como objeto de estudio: un céntrico crucero de la Ciudad de México, conocido como el crucero de El Caballito, por la estatua ecuestre de Carlos IV, que estuvo en él por casi siglo y medio. Estas imágenes son abordadas para evidenciar las implicaciones metodológicas de trabajar con este tipo de documentos en estudios sobre la ciudad, refiriendo los aportes que ha significado el desarrollo de una propuesta de documentación, catalogación y puesta en acceso que se viene efectuando en el Laboratorio Audiovisual de Investigación Social (LAIS) del Instituto Mora.

PALABRAS CLAVE: Ciudad. Espacio urbano. Fotografía aérea. Fuente de investigación. Metodología.
\end{abstract}

RESUMO: $\bigcirc$ texto apresenta algumas possibilidades de pesquisa com fotografias aéreas, focalizando o estudo da cidade. Situado no caso mexicano, esboça um panorama da fotografia aérea no México, para em seguida revisar o potencial desse tipo registro como fonte de pesquisa. $\bigcirc$ corpus visual analisado é constituído por uma trintena de imagens aéreas, que datam de 1932 a 1978, e registram o espaço urbano que se constitui como objeto de estudo: um cruzamento central na Cidade do México, conhecido como o cruzamento de El Caballito, devido à estátua equestre de Carlos IV, nele instalada por quase 150 anos. Tais imagens são abordadas para evidenciar as implicações metodológicas de trabalhar com esse tipo de documentos em estudos sobre a cidade, referindo-se ao significado das contribuições surgidas no desenvolvimento de uma proposta de documentação, catalogação e disponibilidade de acesso levada a efeito no Laboratorio Audiovisual de Investigación Social (Lais) do Instituto Mora.

PALAVRAS-CHAVE: cidade, espaço urbano, fonte de pesquisa, fotografia aérea, metodologia.

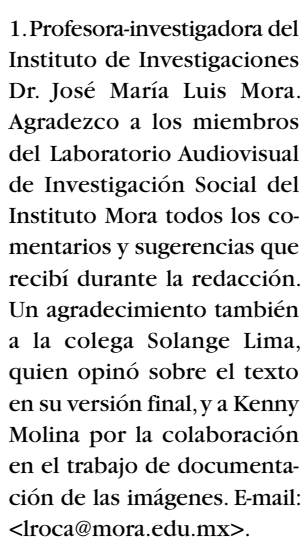

$<$ lroca@mora.edu.mx>. 
ABSTRACT: This article describes possible routes for research using aerial photographs, and focuses especially on the study of urban areas. The specific case considered is that of Mexico. After presenting a panorama of aerial photography in Mexico, we review the potential of this type of record as a primary source for research. The visual corpus analyzed is composed of about 30 aerial photographs, taken between 1932 and 1978. They portray the urban space that is our object of investigation: a downtown intersection in Mexico City, known as el crucero de El Caballito ("the little horse intersection") because an equestrian statue of Carlos IV +was located there for nearly 150 years. We consider the aforementioned photographs of this location in order to demonstrate the methodological implications of working with aerial photographs of cities. The backdrop to this proposal is work on documentation, cataloguing and dissemination undertaken at the Laboratorio Audiovisual de Investigación Social ("Audiovisual Laboratory for Social Research"), at the Instituto Mora.

KEYWORDS: city, urban space, aerial photography, primary sources, methodology.

"La ciudad es la proyección de la sociedad sobre el terreno." Henry Lefebvre, 1978

"La fotografía, además de interpretarla, también captura la realidad."

Susan Sontag, 1996

Preámbulo

En el marco de un estudio sobre las transformaciones de un espacio urbano ubicado en el centro de la Ciudad de México, este texto se detiene a revisar el potencial de la fotografía aérea como fuente de investigación. La mayoría de registros aéreos sistemáticos realizados sobre la ciudad durante buena parte del siglo XX está constituida por documentos inéditos o poco considerados por los estudios urbanos.

Al estudiar los procesos sociales que viven las ciudades y sus habitantes, el trabajo de documentación de estas imágenes permitirá exponer de qué manera se propone la incorporación de este tipo de fuentes en la investigación social sobre la ciudad y lo urbano y, más allá del potencial que pueden tener, cuáles son sus bondades y limitaciones frente a otros documentos fotográficos, así como las implicaciones metodológicas.

Las transformaciones de un espacio urbano están ligadas a muchos tipos de intereses, donde a menudo predominan los económicos y políticos, si bien también los estéticos. En el proceso de concepción, diseño, producción y práctica de estos espacios, las imágenes pueden jugar un papel fundamental. Lo que se captura y se muestra visualmente acerca de ellos puede acompañar textos oficiales, publicitarios, periodísticos y de otro tipo, muchas veces para ilustrar, otras para complementar la información textual y algunas para promover una imagen de cómo puede (o debe) ser y verse la ciudad. Revisaremos de qué manera estas 
ideas condicionan su transformación y suponen concesiones para que los cambios urbanos se den en un sentido $u$ otro.

Como caso de estudio en curso, este texto presenta algunos avances del trabajo de investigación con fotografías aéreas que vengo realizando acerca de un espacio de la Ciudad de México, el céntrico crucero de El Caballito - así conocido por la estatua ecuestre de Carlos IV, obra de Manuel Tolsáz , que permaneció en él por casi siglo y medio -, ubicado en la confluencia del Paseo de Bucareli, el Paseo de la Reforma y la Avenida Juárez. Para ello, nos detendremos primero en los motivos de considerar a la fotografía para estudiar lo urbano y en el desarrollo de la fotografía aérea en México y su potencial para investigar sobre la ciudad en el siglo XX.

El porqué de la fotografía para estudiar la ciudad: otra fuente de investigación

Si toda investigación histórica parte del estudio de los vestigios que han permanecido hasta el presente, cuando investigamos sobre la ciudad podemos encontrar estos legados en escritos, en testimonios y artefactos de distintas épocas, que localizamos y reproducimos, todo para ser analizado desde nuestro tiempo, con preocupaciones y preguntas de hoy, pero con el gran reto de reconstruir hasta donde sea posible el contexto de producción de cada uno de ellos. El ser de la ciudad histórica está en estos escritos, artefactos y testimonios de diversos momentos, sin embargo, también está en los diversos pensamientos y miradas sobre el mundo que los produjo. La principal dificultad de la investigación estriba en desentrañarlos.

Uno de estos artefactos que también dan cuenta del pensar y proceder humanos es la fotografía. Sea con el objetivo de documentar o de expresarse, como resultado de la intervención humana en una situación dada en un tiempo y espacio concretos, la técnica fotográfica permite capturar un registro que, en primera instancia, constituye información icónica codificada por una mirada y, por tanto, desplegada a través de una sintaxis determinada en un momento y lugar particulares. Así, la imagen capturada nos acerca a cómo ve el mundo el fotógrafo y, al mismo tiempo, nos permite acceder a información referente a un momento y espacio dados. Como diría Sontag, la fotografía, además de interpretarla, también captura la realidad ${ }^{3}$.

Para analizar ambos, mirada y contenido icónico, es necesaria una serie de habilidades y conocimientos que nos permita ir más allá de sus comunes usos ilustrativos. El gran problema es que "la función ilustrativa de la fotografía deja intactas las opiniones, los prejuicios, las fantasías y la desinformación"; "las grandes fauces de la modernidad han masticado la realidad y escupido todo el revoltijo en forma de imágenes" ${ }^{4}$, como diría Sontag, por lo que ahora el reto desde la investigación estriba en reconstruir los procesos de conocimiento que aquéllas potencian y que han sido hechos a un lado por largo tiempo.
2. Instalada originalmente en 1796 en el centro de la Plaza de Armas de la Ciudad de México, la escultura fue encerrada por más de tres décadas en el antiguo patio de la Universidad cuando inicia el movimiento de Independencia, y finalmente ubicada en 1852 en el crucero que aquí estamos estudiando, donde iniciaba el Paseo de Bucareli hacia el sur y desembocaba la calzada del Calvario desde el este. Ahí permanecería siglo y medio, hasta que en 1979 fuera trasladada a su actual ubicación, la Plaza de Minería, también conocida como la Plaza Tolsá, frente al Palacio de Minería.

3. Cf. Susan Sontag (1996, p. 16).

4. Idem (2004, p. 98, 127). 
5. Véase Philip Ethington (2000). Apunta a la vez cómo para Benjamin también es crucial la disociación de la fotografía con su referente. Como uno de los primeros en una larga línea de críticos del siglo XX, vio en el realismo estético un peligroso apoyo para la dominación fascista a través de la imagen. Podría decirse que abrió el debate acerca de la posición de la fotografía en la historia y como parte de la historia.

6. Véase Joanna C. Scherer (1992).

7. Con la fotografía aérea tenemos la gran ventaja de conocer por lo menos a sus productores, usualmente grandes empresas que, para el caso de México, estuvieron en gran medida con la industria de la construcción, lo cual será motivo de que más adelante me detenga en su desarrollo en México.

8. Véase Joanna C. Scherer (1992).
Desde que existe la fotografía en su concepción más básica, la cámara oscura, existe su relación con la ciudad. Siglos de representaciones urbanas de carácter más bien estático, inmune al deterioro y la decadencia se ven sacudidos por la invención de la fotografía y la posibilidad de capturar los procesos de modificación urbana. Como heredera de la camera obscura, del diorama y del panorama, se sumó a estos procesos de mediación para el disfrute de la ciudad, más cercanos a una experiencia de espectáculo; sin embargo, también propició el desarrollo de usos documentales, de ahí que en fechas bien tempranas ya contemos con fotógrafos preocupados por utilizar la cámara como instrumento de registro de las vertiginosas transformaciones de las ciudades, sobre todo en Paris; y con ello, dispongamos hoy de otras posibilidades para ver en los resquicios del tiempo y analizar el espacio en infinitas nuevas dimensiones. En este sentido, Ethington se refiere a la fotografía como "la máquina del tiempo"; 5 para él la historia es esencialmente fotográfica, como si el tiempo consistiera en una serie de tomas efímeras; por lo que considera que con la ayuda de la fotografía podemos ver las capas del pasado presente.

Finalmente, apuntando hacia su construcción como fuente, destacamos, de acuerdo con Scherer, que la fotografía puede ser usada como fuente primaria, no a manera de réplica de la realidad por sí misma sino como representación que requiere una interpretación crítica. Para ella, sólo podemos llegar al significado holístico de la fotografía si la consideramos por sí misma como documento/ artefacto, interpretamos su contenido y comprendemos la intención del fotógrafob

Ahora bien, un primer problema lo constituye aquí el simple hecho de localizar las propias imágenes, como también saber quiénes fueron sus autores. Si a veces es difícil dar con la información documental que buscamos en registros oficiales u otro tipo de acervos, la búsqueda de material fotográfico puede ser particularmente complicada porque a menudo vamos a lidiar con las limitaciones de las colecciones y los prejuicios con que están construidas, lo que hace todavía más difícil la identificación de sus productores. Desde luego son más valiosas para nosotros cuando están relacionadas por grupos o series, pero éste no constituye el tipo de material que encontramos de manera general ${ }^{7}$.

Después de localizarlas viene el proceso de descripción y análisis, siempre detallado; las preguntas básicas - quién registró, qué, cuándo, dónde y por qué - no se pueden obviar. A menudo esto nos permite conocer quién tuvo el principal poder de decisión sobre el registro efectuado, pero esto que puede sonar tan sencillo es siempre mucho más complicado de lo que parece. Matices como el objetivo comercial por registrarla, los estereotipos, los gustos de la audiencia que el fotógrafo tiene en mente, entre otros, son importantes a considerar para entender qué fue y qué no fue fotografiado. Pero siempre parece haber una relación entre las intenciones explícitas del hacedor de la imagen, la selección del proceso y los estilos visuales resultantes ${ }^{8}$, como efecto de los cánones fotográficos en que se ha formado o desarrollado profesionalmente el fotógrafo.

Un reto básico es el de aprender con la práctica qué puede ser comprendido a partir de la misma imagen y qué debe ser obtenido a partir de materiales documentales relacionados, lo que contemplamos desde la construcción 
de la propia ficha de documentación que ocupamos en el Laboratorio Audiovisual de Investigación Social (Lais) del Instituto Mora, basada en la Norma Internacional de Descripción Archivística Isad(G) - General International Standard Archival Description -ampliamente referida en la Introducción y en los Lineamientos para la descripción de fotografías de nuestro libro próximo a publicar?

Pero retomando el asunto de lo urbano y sin perder de vista que estamos trabajando sobre un espacio céntrico de una gran urbe, lo caracterizaremos de inicio (con el apoyo en Lefebvre) como un núcleo urbano que sobrevive gracias a su doble función de lugar de consumo y consumo de lugar: 10 lo primero, en la medida en que ha sido un lugar sumamente practicado por la población desde que apenas fue trazado como punto de encuentro de paseos, tan usados sobre todo para el esparcimiento de los habitantes; lo segundo, en tanto ha sido foco de grandes intereses económicos y motivo de magnas inversiones, también desde ese mismo inicio. Este enfoque ubica al espacio urbano en relación con lo políticoeconómico y su intervención urbanística, sobre todo porque ha sido estratégico, aunque no siempre logremos encontrar huellas tan evidentes de ello. El espacio se forma, se modela, a partir de elementos históricos o naturales, pero siempre políticamente, porque es una representación literalmente plagada de ideología, es un producto social ${ }^{11}$.

De ahí la concepción lefebvriana de lo urbano frente a la ciudad, de la cual se distingue precisamente porque aparece y se manifiesta en el curso de la dispersión de la ciudad, en nuestro caso justo con la conformación de este crucero que con el tiempo detonaría los usos sociales del Paseo de Bucareli a fines del siglo XVIII, ya eminentemente urbanos, en conjunción con los propósitos de extender la ciudad hacia el poniente y la consiguiente creación casi un siglo después del Paseo de la Reforma (concebido de inicio en pleno Imperio como Paseo de la Emperatriz). $Y$ es justo este carácter urbano lo que permite reconsiderar y comprender determinados aspectos de la ciudad, aspectos que pueden pasar a menudo inadvertidos por mucho tiempo: la centralización, el espacio como punto de reunión, la monumentalidad, entre otros ${ }^{12}$, todos ellos presentes en el espacio aquí estudiado.

A través de las contradicciones existentes entre el hábitat, las segregaciones y la centralización urbana - que resulta esencial para la práctica social -, se pone de manifiesto esta contradicción llena de sentido que es lo urbano. De ahí que con Lefebvre consideremos al espacio sobre todo como visual, donde impera la dictadura del ojo ${ }^{13}$, no sin riesgo de conflicto, porque lo visual se contenta con la representación bajo forma de imágenes; pero aquí pensando en imágenes sobre todo de amplio espectro, si vale la analogía, ya que la fotografía aérea justo nos conduce a analizar este microespacio en función del gran paréntesis que lo enmarca, conformado básicamente por lo que hoy llamamos el centro de la ciudad y su rumbo poniente.

Y precisamente de entre esas imágenes, antes de la posibilidad de fotografiar desde un avión la capacidad de síntesis de esos registros resultaba inimaginable, porque las vistas aéreas dibujadas y pintadas plasmaban otro tipo de síntesis del espacio. Desde mediados de siglo XX, Chombart afirmó que aquélla ofrecía visiones de conjunto de la humanidad y las interacciones a su interior, así
9. Véase Fernando Aguayo y Lourdes Roca (inédito).

10. Cf. Henri Lefebvre (1978, p. 27-28).

11. Idem (1976, p. 46).

12. Idem (1976, p. 67-68).

13. Idem (1976, p. 124): "Las torres, los monumentos se erigen por encima de los suelos y superficies, de las insipideces, no para decir y llevar a cabo alguna cosa, sino para poder controlar y vigilar mejor. Esas fuerzas rigurosas y vigorosas mantienen de esta guisa un tiempo, el del orden (moral)". 
14. Cf. Paul Chombart De Lauwe (1956, p. 5-7).

15. Cf.Jean-Marc Besse (2003, p. 355).

16. Cf. Rosalind Krauss (2002, p. 40-59).

17. Idem (2002, p. 26).

18. Esto se ve claramente si contrastamos, por ejemplo, la Imagen 1 con la Imagen 2, en que se ven mucho mejor los distintos planos perpendiculares al terreno, que a fin de cuentas es lo que permite de particular una oblicua frente a una vertical. como con el medio ambiente, lo cual debería permitir síntesis que difícilmente podríamos concebir sin este tipo de registros ${ }^{14}$. De acuerdo con Besse, la fotografía aérea debe permitirnos el análisis de la "profundidad temporal del paisaje" 15 como documento humano; de ahí la ilustrativa analogía que hace con un hojaldre, que permitiría ir separando capa por capa y ver lo que alguna vez estuvo ahí, aunque ya no esté, así como analizar de qué manera se fueron dando los traslapes y qué quedó en lugar de qué; todo un reto para la investigación con las que han capturado la ciudad, sobre todo por la cantidad y densidad de información que contienen.

La fotografía posibilitó otras formas de ver: desde entonces lo visual es también fotográfico. Si de acuerdo con Krauss cada imagen actúa en un espacio discursivo distinto ${ }^{16}$, habrá que trabajar sobre cuál es en específico el de la fotografía. Esto nos lleva ineludiblemente al tema de la veracidad en las imágenes, objeto de discusión desde hace siglos, pero que lo fotográfico pone en crisis.

Para detenernos en qué nos permite conocer la fotografía aérea, aportes como los que hizo Chombart'7 hace más de medio siglo serán de primera importancia. En primer lugar nos revela las limitaciones de las fotografías aéreas oblicuas capturadas a $30^{\circ} \circ 60^{\circ}$ de ángulo con la horizontal de la superficie terrestre, frente a las de $45^{\circ}$, ángulo más recomendable para este tipo de registros ${ }^{18}$. Por otro lado, nos advierte que el contar con pequeñas secuencias de

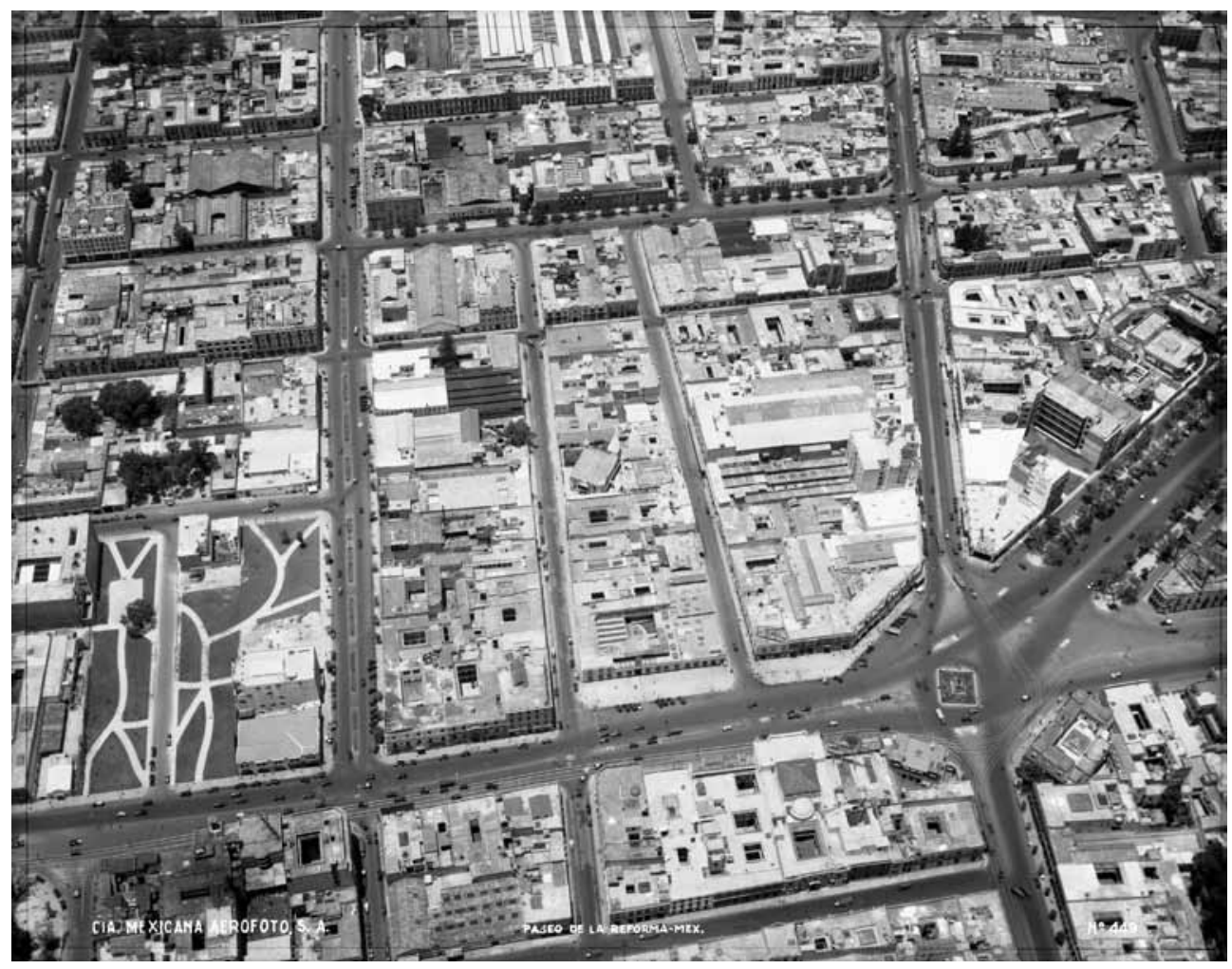

Imagen 1 - MxIM-2-3-3-1 (Estructura del código de referencia: MX - México; IM - Instituto Mora; 2 -Colección El Caballito; 3 - Grupo documental Desde el aire), Compañía Mexicana de Aerofoto, Ciudad de México, 1932. In: Compañía Mexicana de Aerofoto, 449. 


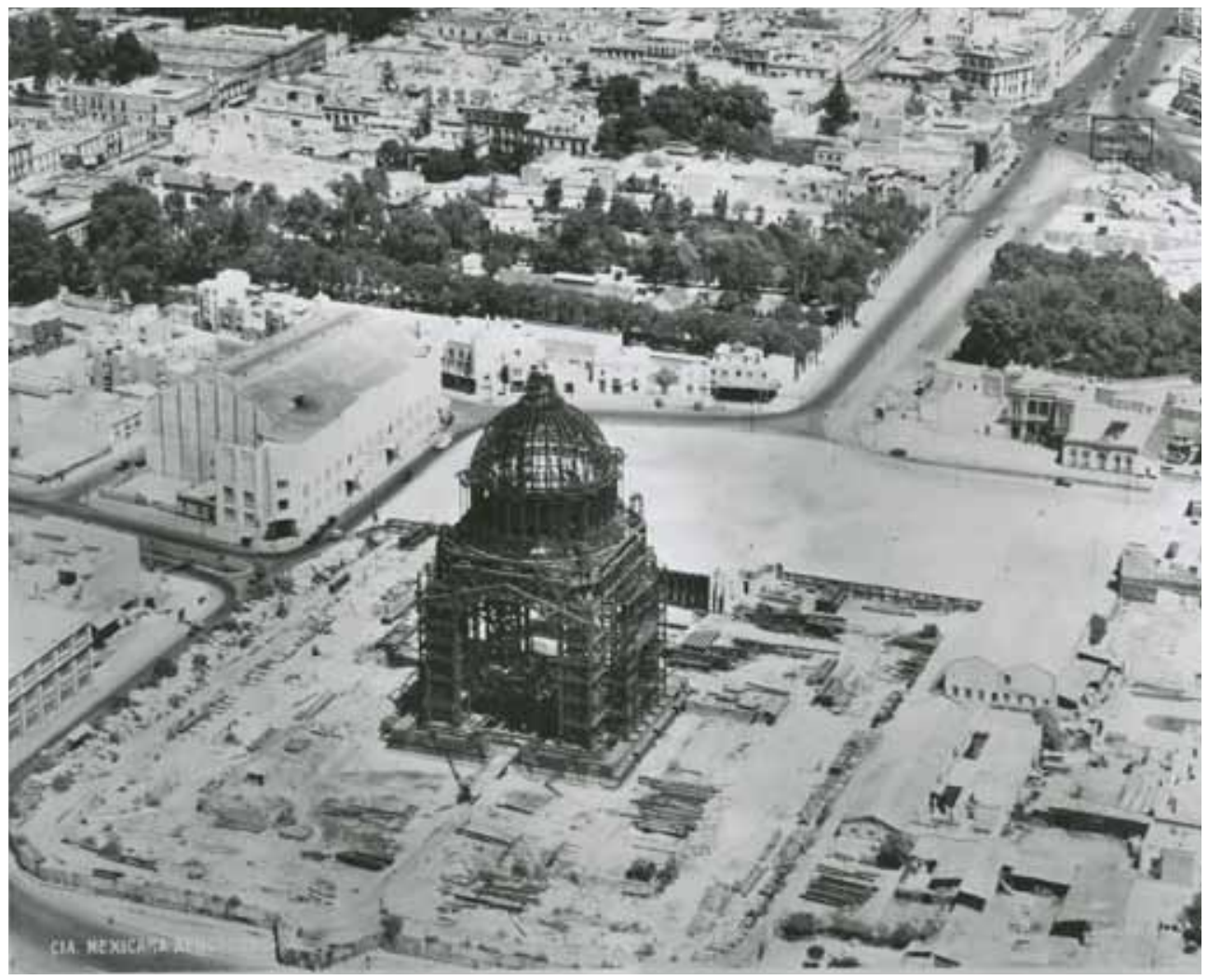

Imagen 2 - mxiM-2-3-3-3, Compañía Mexicana de Aerofoto, Ciudad de México, 1932. In: Compañía Mexicana de Aerofoto, 403.

viraje circular sobre un espacio urbano, lo que a veces resulta en alguno de los vuelos efectuados ${ }^{19}$, también ayuda sobremanera por la mirada concéntrica que se logra sobre él, permitiendo documentarlo con mayor precisión al facilitar su estudio desde puntos de captura consecutivos.

Veremos qué pueden respondernos las fotografías aéreas abordadas para poner en tela de juicio esta posibilidad que venimos proponiendo de conocer sobre la ciudad a través de ellas: la especificidad de lo fotográfico aéreo en el marco de lo urbano será la materia de análisis, sin olvidar primero que nada que el espacio se volvió la mercancía universal por excelencia - produce interacciones sociales a la vez que éstas lo producen en relaciones de interés, prácticas e intercambios -, por lo que no es "inocente" y sirve a la reproducción social ${ }^{20}$, como veremos de diversas maneras con la interpretación del microespacio retratado.

Ecos fotográficos: a propósito de la planificación urbana y sus órganos de difusión

La forma del espacio social es el encuentro, la reunión, la simultaneidad, mientras que el espacio-naturaleza contrapone, dispersa, de acuerdo a las teorías
19. Sólo contamos con un registro secuencial de este tipo, que será trabajado cuando se integre la totalidad de las aéreas al análisis en curso.

20. Cf. Milton Santos (2002,p. 21; 1990, p. 156)

Annals of Museu Paulista. v. 19. n.1. July.-Dec. 2011. 
21. Idem (2002, p. 123).

22. Lista de miembros activos de la Asociación: Ignacio Avilés, Ladrillera La Huerta Compañía Minera Las Dos Estrellas, Federico Mariscal, Carlos Obregón Santacilia, entre muchos otros particulares y empresas con capital, interesados e involucrados en las transformaciones urbanísticas, arquitectónicas, de uso de suelo y especulación y proyección inmobiliaria del momento (Planificación, n. 5, enero 1928).

23. Cf. Planificación, n. 1 , sept. 1927 , p. 3 .

24. No olvidemos que Contreras se formó en la Universidad de Columbia y fue uno de los principales introductores de la planificación urbana funcionalista en los inicios de la gestión de los primeros regímenes posrevolucionarios. Concibió el Primer Congreso Mexicano de Planificación de Ciudades, que finalmente tuvo lugar en 1927. Su línea principal de trabajo promovía cómo "ordenar" el "desorden" urbano, sobre todo a través de generar la transformación urbana rentable. Uno de los significados históricos de Contreras es el de haber sido un modernizador, acorde con la ideología industrialista y populista del maximato. Aunque las propuestas de Carlos Contreras no fueron aplicadas en toda su extensión, quedan como un referente importante de la ulterior política de planificación urbana, sobre todo de la Ciudad de México. Véase Rafael López Rangel (2003). lefebvrianas. Si el espacio solo fuera físico, esto sería totalmente verdadero, pero el espacio social se distingue de las formas inhabitadas por el propio hecho de su complicidad con la estructura social: con las fuerzas productivas y la división del trabajo que ahí se manifiestan, el espacio es también una herramienta para profundizar las diferencias de clases, es decir, "el espacio une y separa a la vez a los hombres"21. Para entender mejor este planteamiento veamos cuáles son las ideas que prevalecen sobre la ciudad en el momento en que la aviación se instaura para quedarse.

Precisemos algunos antecedentes sobre la planificación urbana de la Ciudad de México en los años veinte, para después describir lo que observamos acerca de este espacio urbano a partir de la descripción y análisis del conjunto de aerofotos abordadas, y finalmente apuntar algunas posibles interpretaciones que habrá que contrastar con lo que nos permita la siguiente etapa de investigación con el corpus fotográfico registrado a otros niveles de la superficie urbana (desde diferentes alturas y a pie de calle).

Acerca del periodo que anticipa este tipo de registros, la década de los años 1920, vale la pena tomar nota de lo que sigue, para ver si podemos entender de manera más cabal las coordenadas espacio temporales de la ciudad justo cuando retratarla desde el aire se convierte en una práctica constante. Varias revistas de finales de los 1920, de las que destaco Planificación, Obras públicas, y Nuestra ciudad, servirán para referir diversos aspectos sobre la concepción de la ciudad del momento, su ser y deber ser, su proyección, todos ellos relativos a las reflexiones que buscamos construir aquí. Las dos primeras tienen un carácter especializado y la última es para un público más amplio, por lo que nos permiten contrastar el uso de las imágenes de la ciudad como ecos fotográficos, incluidas las propias aéreas, así como re-hilvanar mejor el discurso que se venía construyendo sobre cómo debía ser y verse la ciudad según el funcionalismo que se iba introduciendo en las ideas y concepciones del futuro urbano.

La revista Planificación, dirigida por el arquitecto Carlos Contreras abanderado de la "Reconstrucción Nacional" posrevolucionaria y creador del Plano Regulador del Distrito Federal que desarrollará en la siguiente década -, planteaba desde su primer número con un editorial del Doctor Atl que aspiraba a la creación del Ministerio de Planificación; esto sólo para ver las expectativas gubernamentales que en el momento se tenía en torno a cómo planificar las ciudades y, sobre todo, la ciudad capital, y cómo las propagaban y reforzaban cotidianamente diversos órganos de difusión como esta publicación.

La fundación de la Asociación Nacional para la Planificación de la República Mexicana 22 por parte de Carlos Contreras tenía como programa "la trasformación de la República, empezando por convertir la Ciudad de México en una ciudad moderna, cómoda, limpia, bella"23. El modelo a seguir para entonces ya era el del funcionalismo que venía imperando en Estados Unidos, por lo que todas las referencias sobre cómo debían idearse y realizarse las transformaciones de la ciudad tenían su referente en ejemplos de ciudades estadounidenses y reflexiones y teorías que circulaban allá, a menudo hasta con la colaboración escrita de gerentes de planificación de varias ciudades del país vecino ${ }^{24}$. 
Un problema que se apuntaba de manera reiterada era el del tráfico: si en 1911 en la ciudad circulaban seis mil automotores, para 1924 la cifra se había más que doblado a 13 mil; y se calculaba llegar a 250 mil para 1950. Las propuestas y modelos a seguir para evitar que la ciudad se convirtiera en un caos eran numerosos. La fotografía se utilizaba seguido, por cierto, como elemento para comprobar en público que había puntos particulares de congestionamiento vial cada vez más alarmantes, como argumento básico para defender sus proyectos de remodelación de cruceros, sentidos de las calles, ampliación de vialidades, creación de pasos subterráneos y, sobre todo, de grandes avenidas, para lo que desde luego las ciudades estadounidenses eran el gran modelo a seguir. Obras públicas, órgano del Departamento del Distrito Federal, quizá sea el mejor ejemplo en el uso reiterado de las fotografías con esta intención, siempre identificándolas sobre todo espacialmente con detalle e incluso utilizando la edición para enmarcarlas y resaltar unas sobre otras o establecer elementos de contraste a los ojos del lector. Así como también destaca esta publicación en el ejemplo reiterado de experiencias y proyectos de ciudades estadounidenses ${ }^{25}$.

Llama la atención también que, para el número 5 de Planificación (enero de 1928) y en el marco de la proliferación de los primeros vuelos experimentales sobre ciudades, ya se habla de la foto-topografía aérea y sus aplicaciones prácticas, como "ciencia que se ocupa del levantamiento de planos topográficos por medio de fotografías a escala, tomadas desde un aeroplano" 26 . En él mencionan la distinción básica que prevalece a la fecha en los usos de estas imágenes entre la toma oblicua o plano-perspectiva, a la que adjudicaban un valor sólo comercial como anuncio, y la vertical, utilizada en trabajos "científicos" y a menudo tildada de "mapa aéreo".

En pluma del ingeniero Francisco Antúnez, quien elaboró el anteproyecto de rutas aéreas para la República Mexicana, incorporaban a este número de la revista las que consideraban que eran sus principales aplicaciones prácticas en localización de líneas de alta tensión, trabajos de construcción de presas, puertos, estudios sobre forestación, agronómicos, de localización de ferrocarriles y carreteras, de valor de suelo, etc., entre las cuales destaco las siguientes:

Planificación y zonificación de ciudades, en las que su utilidad es extraordinaria, porque permite formarse una idea exacta y concreta de la clase de construcciones; del valor de éstas, de la manera como están distribuidos sus parques y jardines; del alineamiento de las avenidas y calles; de la topografía del terreno; establece la relación precisa de unos elementos de la ciudad con relación a otros; fija la posición de los ríos, montañas, arboledas, presas, canales, obras de desagüe, etc. Facilita, en suma, la labor de proyectar juiciosamente las mejoras municipales, la ampliación de calles y la apertura de nuevas avenidas.

Planificación de regiones, permitiendo obtener una visión amplia del conjunto de una comarca o distrito y una idea exacta del relieve y accidentes del terreno. Facilita en tal concepto la tarea de proyectar las obras públicas correlativas, tales como sistemas de captación de aguas, introducción de aguas potables, drenaje, transmisión de energía eléctrica, etc.

Cuando dos ciudades están separadas por distancias comparativamente cortas, puede decirse que sus problemas no son propios, sino regionales, a causa de la mutua influencia que
25.A tal grado las referencias al vecino país permean el discurso que incluso los términos utilizados presentan alteraciones interesantes, como el uso reiterado del término "sugestión" para referirse a sugerencia.

26. Véase Planificación, n. 5 , enero 1928, p. 13. 
27. Ibidem.

28. Véase, en la Mapoteca Orozco y Berra, del Servicio de Información Agroalimentaria y Pesquera (Sagarpa), Joseph Antoine Decaen y Victor Debray (1866). Colección Orozco y Berra D.F. Varilla 03 951-OYB-725.

29. Obras públicas, n. 4 , abr. 1930.

30. Nuestra ciudad, n. 1, abr. 1930. ejercen entre sí, y es entonces cuando los mapas aéreos prestan su mayor utilidad, permitiendo abrazar el problema de conjunto.

Estudios sobre el tráfico de una ciudad. En este caso, simultáneamente con el levantamiento foto-topográfico, se hace el recuento de automóviles y carros, estudiándose en los cruceros las corrientes de tráfico, a fin de poder establecer relaciones entre el número de autos comprendidos dentro de un área dada y la velocidad, así como la cantidad de éstos que pasan por un crucero dentro de un tiempo dado. [...]

Existen otra multitud de aplicaciones de la fotografía aérea, que con las anteriores están llamadas a efectuar una verdadera revolución en los métodos topográficos y en los usos de éstos, y con tanta mayor razón, cuanto que los resultados obtenidos son muy precisos, pues en un trabajo cuidadoso el error no es mayor de $1 \%$ y la rapidez es incomparablemente mayor con la fotografía aérea que con los procedimientos de antaño.

Ing. Francisco Antúnez Echagaray ${ }^{27}$

Nos atañen en particular aquí estos puntos referidos, por apuntar justo a dos aspectos sobre los que las fotografías revelan varias preocupaciones:

1. el afán de proyectar y ordenar la ciudad y, sobre todo, planificar y urbanizar con el diseño de grandes cruceros y vialidades, lo que implicó un valor en el uso de suelo que fue escalando hasta ser, para el caso concreto del crucero que nos atañe, de los más preciados de la ciudad; así como

2. el hacer observaciones y estimaciones sobre la cuestión del tráfico.

A propósito de este espacio urbano, no podemos dejar de referir la tradición de siglos de fomentar el crecimiento de la ciudad hacia el poniente, cuyo potencial se transforma radicalmente con el trazado del Paseo de la Emperatriz (que luego será el Paseo de la Reforma) durante el imperio de Maximiliano, que buscó unir la ciudad con Chapultepec y la residencia imperial, lo que convirtió a los terrenos aledaños a esta vialidad en los más cotizados de la futura urbe ${ }^{28}$. En relación con esto, resulta interesante mencionar que años después, para 1930, justo se anuncien los terrenos de la colonia Anzures, ubicados en las inmediaciones del cerro de Chapultepec, como los "mejores de la ciudad"29.

Pero si el uso de fotografías en este tipo de revistas comienza a ser usual, otro órgano del departamento del Distrito Federal con un mayor carácter de divulgación, la revista Nuestra ciudad, incluye artículos más cortos y hace uso todavía de más fotografías, también aéreas, pero aquí sin referencia ni crédito alguno, destacando su uso ya no tanto como documento que compruebe un problema o permita justificar una propuesta, sino más bien estético y sobre todo adulador: se regocija constantemente en la inclusión de imágenes que destaquen la belleza o grandiosidad de la ciudad, para lo cual la fotografía aérea, en particular la oblicua, tiene un efecto único. Así, considera secciones como: Estatuas y monumentos; Descubriendo la ciudad de los palacios; Como era México antes de la conquista; Los grandes edificios de nuestra ciudad; Del México que desaparece; Historias y leyendas de las calles de México, etc.; y afirma el carácter de México como "centro aeronáutico"30. 
Desde luego no pueden faltar las fotografías de la glorieta que aquí nos incumbe y sus alrededores, incluso también con registros desde el aire y el énfasis permanente en el problema del tránsito en la ciudad moderna. Resulta de particular interés que, para el caso de esta revista, los usos de la fotografía tengan relación incluso con sus modos de promocionarse, por lo menos en dos números de 1930, con anuncio a toda página y con gran signo de exclamación:

Por $\$ 3.00$ que usted nos envíe, nosotros le devolvemos $\$ 6.00$, aclarando que si te suscribes, además de recibir la revista recibes una fotografía - no grabado - impresa en magnífico papel de $74 \times 11$ o de $54 \times 11$ a escoger de los siguientes lugares: vista panorámica que abarca la Plaza de la Constitución, tomada desde el lado norte y en la que se destaca principalmente la catedral, el sagrario y el palacio municipal; vista panorámica de la Plaza de la Constitución en la que destaca en primer término la catedral y a los lados el palacio nacional y el palacio municipal; vista panorámica del lago de Chapultepec; perspectiva aérea de la Ciudad de México; o vista panorámica de la plaza de toros "el toreo", llena de concurrencia ${ }^{31}$.

El uso de las fotografías urbanas no sólo es profuso en esta publicación, sino también las referencias textuales a ellas, por ejemplo con una oda, en buena parte de un número, al trabajo fotográfico de Hugo Brehme, ampliamente reconocido en 1929 con una magna exposición. El tono siempre patriótico se exalta ya para los números de verano y otoño, que destacan todas las maravillas del país promocionándolo frente al potencial turismo internacional, salpicando el discurso de citas como la de Alberto J. Pani, quien asegura que "el verdadero problema de México consiste en higienizar física y moralmente la población y procurar, por todos los medios, una mejoría en la precaria situación económica de nuestro proletariado"32.

La aviación en la vida mexicana es vista con este mismo tono patriótico y nacionalista en pro del progreso en manos nacionales, sobre todo en el marco del recién logrado primer vuelo Nueva York-Ciudad de México. Como paradigma de todo el tono de la revista y parafraseando su propio título, en su número de octubre ${ }^{33}$ construye otra oda, ahora a la Asociación Mexicana de Aeronáutica, por una formación de la conciencia aeronáutica nacional, y asegurando que pronto habrá un potente avión de transporte de pasajeros y carga con el nombre de Nuestra Ciudad, así como en Nueva York existe un Our City en honor a Nueva York.

Pero pasemos en concreto a la construcción del cuerpo visual de fotografías aéreas como fuentes para ver hasta dónde nos permite entender mejor la transformación de este espacio en este periodo, con la hipótesis de que ha sido diseñado en gran medida para invertir en él a fin de ser visto y admirado como una de las principales ventanas visuales a la Ciudad de México, donde destacan tres de sus principales rascacielos, incluido uno de los primeros construidos por la Lotería Nacional ya hace cerca de setenta años (El Moro, en 1946).
31. Nuestra ciudad, n. 3, jun. 1930, p. 1 .

32. Ibidem, p. 64.

33. Nuestra ciudad, n. 7, oct. 1930, p. 76. 
34. Para más detalles sobre este proceso, véanse Introducción y Lineamientos, en Fernando Aguayo y Lourdes Roca (inédito)

35. El Pescador inició su desarrollo en 2002 y ha avanzado a partir de diversos proyectos. Para más información véanse las fototecas digitales: Fotógrafos $y$ editores franceses en México, siglo XIX (disponible en $<$ http://lais.mora.edu/ff $>$ ) y Marcas de fuego (disponible en <www.marcasdefuego. buap.mx>); así como diversos textos en línea acerca del proceso de desarrollo del Sistema de Información para Archivos de Imágenes, $\mathrm{El}$ Pescador, sobre el que funcionan dichas fototecas (disponible en <http://durito. nongnu.org $>$ )

36. Cabe precisar que la Compañía fue adquirida en 1965 por Ingenieros Civiles Asociados, que era una de sus principales clientes. Cf. Fernando Osorio y Nareni Pliego (2007, p. 28).

37. Como los publicados por la historiadora Alejandrina Escudero o por la propia Ingenieros Civiles Asociados (ICA).
Fotografías aéreas para entender lo urbano

Veamos a continuación cómo es que podemos conocer más acerca de este pequeño recorte estratégico de la ciudad y sus transformaciones a partir de fotografías aéreas, para entender mejor cómo se ha mirado y cómo se ha querido que sea visto este espacio urbano, lo que de hecho no podremos comprender cabalmente hasta completar la investigación con los demás registros fotográficos capturados desde otros niveles. El primer paso que hemos establecido ha sido la necesaria documentación de todas las fotografías, a partir de unos Lineamientos para la Descripción de Fotografías implementados (como decíamos atrás) en el Laboratorio Audiovisual de Investigación Social (Lais) del Instituto Mora, con base en la Norma Isad $(G)^{34}$, sumandose un análisis comparativo y una interpretación a la luz de su confrontación con otro tipo de documentos fotográficos y textuales.

Acerca de la documentación, la consignación de información básica relativa a la identificación, contexto, estructura y contenido, características físicas y documentación asociada de estas imágenes permite ubicarlas y normalizar los datos para su recuperación en cualquier otro momento y por cualquier otra persona, a partir de su futura puesta en acceso con El Pescador - el Sistema de Información para Archivos de Imágenes que el Lais ha desarrollado y puesto en línea en los últimos años ${ }^{35}$. Para una mayor claridad sobre el tipo de documentos que estamos revisando, de todos estos aspectos que reflejan las respectivas áreas de descripción archivística de la norma mencionada, retomaremos en primer lugar algunos aspectos relacionados con las áreas de "condiciones físicas" y "contexto" de los materiales. Éstas ayudarán a tener más definidas las características y estado de las piezas que preservan los archivos, así como los motivos y condiciones de producción de los registros que realizaron estas empresas. Finalmente, nos centraremos en las áreas conocidas como de "estructura y contenido" y "documentación asociada", que nos llevarán a describir y analizar lo que estuvo frente a la cámara en el momento de estas capturas y las formas en que se hicieron.

De las piezas y sus contextos de producción

En relación al área de contexto, es preciso apuntar que la mayoría procede del acervo que recientemente ha buscado más la preservación, digitalización y acceso a la fotografía generada por la Compañía Mexicana de Aerofoto desde sus orígenes, que es el de la Fundación ICA ${ }^{36}$. Enseguida tenemos en menor proporción imágenes que preserva una oficina de vuelos en activo que sobrevive de lo que fue la Compañía Mexicana de Aerofoto, y las que ha generado también Struck Fotogramétrica Internacional desde los años sesenta. Debido a los escasos textos que refieren el desarrollo de la fotografía aérea en México ${ }^{37}$, profundizo enseguida en un panorama general. 
Por supuesto tenemos antecedentes de representaciones aéreas de la ciudad desde fines del siglo XVIII, con las posibilidades que ofrecieron los vuelos en globo aerostático; sin embargo, refiriéndonos ya en concreto a las posibilidades que abrió la tecnología aeronáutica en el siglo XX, destaco el hecho de que especializarse como piloto de aviones destinados a la fotografía aérea llegó a ser muy redituable: ${ }^{38}$ había muy pocos. En el marco sobre todo del avilacamachismo y el proyecto de Unidad Nacional el auge de la aviación quedó estrechamente vinculado a la guerra y sus distintas tácticas: los pilotos fueron formados como pilotos de pelea y los primeros aviones utilizados de manera sistemática con este fin serían bombarderos. El objetivo era estrictamente militar ${ }^{39}$, no sólo había que reconocer el territorio nacional a detalle sino que había que construir formas de controlarlo. Detrás de todos estos proyectos tuvo un papel fundamental Estados Unidos y sus ideas de seguridad nacional y cultura industrial en la coyuntura del fin de la Segunda Guerra y los inicios de la posguerra. De hecho, los equipos y aparatos destinados a la construcción de esta técnica de reconocimiento territorial serían todos estadounidenses, generalmente desechados por caducos o inservibles por el vecino país del norte.

Aquí cabría la analogía entre los afanes de orden y control por parte de las teorías de planificación urbana que venían imperando desde los años veinte en el país y el objetivo también controlador del apuntalamiento de la fotografía aérea, como una práctica sostenida primero por el Servicio Cartográfico Militar ${ }^{40}$, con mucha libertad en el proceso de trabajo de pilotos y camarógrafos, para desembocar en pocos años, con la creación del Escuadrón de Fotografía, en una práctica estrictamente reglamentada y jerarquizada que alejó a más de un piloto de los que se iniciaron en el Servicio Cartográfico Militar, como fue el caso del capitán Ovando, que para entonces decide mudarse a la empresa privada para seguir ofreciendo los servicios de registro fotográfico desde vuelos a diversas escalas a petición de particulares, como la Compañía Mexicana de Aerofoto.

Sobre el método de trabajo nos interesa rescatar que el desempeño en el aire dependía en gran medida de las observaciones e indicaciones de meteorólogos con los que los pilotos llegaban a establecer estrechas relaciones de amistad. La vida cotidiana y la rutina laboral estaban sujetas sobre todo a los lineamientos que estos colegas ofrecían para los vuelos a realizar: los destinos norte, sur, este, oeste, los días de vuelo o de descanso, los horarios para realizarlos, entre otros detalles, dependían siempre de lo que aquellos recomendaran. De nuevo vemos como evidente la trascendencia de las condiciones climáticas en este oficio.

En el momento en que proliferan las empresas comerciales destinadas a ofrecer servicios de registro fotográfico aéreo, los pilotos de aviación que optan por esta especialización se convierten en unos de los profesionales mejor pagados y de mayor prestigio, imbricado en gran parte con el del papel de la aviación mexicana en la Segunda Guerra ${ }^{41}$. Esto conllevó una carrera por la máxima eficiencia y precisión que implicó experimentar cada vez con mejores equipos y generar mucha competencia en el medio para ver quién podía hacer los registros con mayor calidad y mejor pericia, lo que implicaba ser muy diestro en el manejo
38. En adelante, retomo opiniones vertidas por el capitán Efraín Ovando en: Entrevista con el capitán Efraín Ovando, el 3 de julio de 2009 , realizada por Lourdes Roca, en Los Reyes, Coyoacan, Ciudad de México. En la entrevista, este capitán retirado enfatiza el prestigio del oficio, por las ganancias que en su momento permitía redituar, sobre todo cuando el Estado deja de tener el control sobre esta práctica de registro fotográfico y proliferan las empresas comerciales que contratan a pilotos para realizar los vuelos, para lo cual se requería particular pericia, un aspecto a destacar en la trayectoria del capitán Ovando, considerado uno de los más hábiles para realizar vuelos con este fin. Llama la atención que para los años cincuenta este especialista llegara a percibir hasta cincuenta mil pesos en una jornada.

39. De hecho, la formación original de estos pilotos que se iniciaron en el manejo de naves exclusivamente para captura fotográfica era militar; ya después de formarse militarmente en la aviación era que incursionaban en esta línea de especialización implicada en los vuelos para registros fotográficos del territorio.

40. Cuyo antecedente directo es la creación de la Comisión Geográfica Militar, en febrero de 1939, con el encargo de formar la Carta Militar de la República y de realizar estudios de la Defensa Nacional relacionados con la Geografía. Se propuso llevar a la práctica un programa consistente en formar una carta de la República Mexicana en escala 1 : 100000 utilizando fotografias aéreas. El proyecto se inició en 1942. Las primeras hojas fueron elaboradas con fotografías aéreas del sistema trimetrogón, consistente en una cámara central de eje óptico vertical y dos cámaras laterales (izquierda y de- 
recha) de eje inclinado. Estas fotografías fueron tomadas durante la Segunda Guerra Mundial por tripulaciones mexicano-norteamericanas [sic]. Véanse las referencias publicadas al respecto por el Inegi (Departamento Cartográfico) (disponible en $<$ http://mapserver.inegi. gob.mx/geografia/espanol/ prodyserv/marcoteo/dias/ dias.cfm?c=237 >) y por la Sedena (Dirección General de Cartografía) (disponible en $<$ http://www.sedena.gob. $\mathrm{mx} /$ index.php?id_art=25>) (consultados en mayo de 2010).

41. A la fecha, experiencias como la del capitán Ovando tienen su reconocimiento anclado también en el imaginario colectivo de los años 1940 sobre el heroísmo de quienes participaron en el Escuadrón 201 y consiguientes. Caminar apenas un par de cuadras con él por el viejo pueblo de Los Reyes, en Coyoacan, fue suficiente para observar diversos saludos de lo más solemnes dirigidos al "capitán", quien a la fecha acostumbra a adornar su solapa con un pin del Escuadrón 201.

42. Siendo Presidente Constitucional de los Estados Unidos Mexicanos el C. General de División Manuel Avila Camacho y Secretario de la Defensa Nacional el de igual grado Lázaro Cárdenas del Río, se expidió, el 5 de enero de 1942, el Decreto Presidencial en el cual se creaba la Escuela Militar de Mecánicos Especialistas en Aviación (Emmea), la cual tuvo como primer alojamiento un hangar en el Segundo Regimiento Aéreo, ubicado en los llanos de Balbuena, D.F. Seis meses después de haber ocupado las instalaciones antes señaladas (julio de 1942), se le designaron las instalaciones del edificio Azcárate, ubicado en lo que hoy se conoce como el Centro Internacional de Adiestramiento de Aviación Civil (Ciaac), en el aeropuerto internacional de la Ciudad de la nave para mantener las líneas de registro con la mayor rectitud y estabilidad posibles contra la deriva.

La formación de todos ellos fue con especialistas y equipos estadounidenses, lo que desde un inicio construyó una gran dependencia de este país en todos los aspectos que atañen al oficio, sobre todo los de adquisición de equipo, mantenimiento y capacitación. El Centro Internacional de Adiestramiento de Aviación Civil (Ciaac) ${ }^{42}$ fue el espacio en el que la práctica construida con horas y horas de vuelo se profesionalizó. Curiosamente, llama la atención que, frente a lo sofisticado que la caracteriza desde un inicio, hoy día, la fotografía aérea - además de considerarse una práctica muy especializada que básicamente sirve para la construcción cartográfica y remite directamente a instancias como el Instituto Nacional de Estadística y Geografía (Inegi) - deba su popularización a lo llamativo y espectacular de las tomas oblicuas y urbanas en particular, las cuales siguen siendo muy preciadas en el ámbito comercial, sobre todo publicitario ${ }^{43}$.

Respecto a sus orígenes, cabe destacar aquí lo que atañe sobre todo a las intenciones detrás de este tipo de registros, en particular los de tipo vertical o cenital, que predominan y tienen su origen en la búsqueda de control y defensa del territorio, para después aplicarse sobre todo en topografía urbana y reconocimiento del territorio. Por tanto, se buscaba que la construcción de registros permitiera el mayor detalle posible, ya fuera con visiones más globales desde mucha altura como para construir planos y mapas, o con visiones más cercanas desde vuelos bajos que permitieran ver los más mínimos cambios en un predio u obra. Por otro lado, con un carácter mucho menos riguroso, espontáneas, técnicamente mucho más sencillas y estéticamente mucho más llamativas, las oblicuas tenían un uso más enfocado a la promoción, difusión y publicidad de los espacios urbanos, por su vistosidad. Y ya que nos detenemos en las formas de registro vale también la pena apuntar lo que quizá ya parece una obviedad: no todas las épocas, ni climas, ni horas, son adecuados para este tipo de registros, lo que ya condiciona en gran medida nuestras posibilidades de conocimiento del territorio, igualmente del urbano. Por eso era tan importante contar con el apoyo permanente de un meteorólogo.

En época de lluvias, muy rara vez se hacen registros verticales (es difícil encontrar uno capturado entre julio y septiembre que no sea oblicuo ${ }^{44}$ ), por lo que la gran mayoría de vuelos con los que contamos para estudiar la ciudad corresponden a la época de secas; de la misma forma, las horas extremas, ya sea muy temprano o muy tarde no son muy funcionales porque las sombras son demasiado largas y reducen las posibilidades de reconocimiento del territorio. De esta manera, los registros que nos permiten ver mejor la traza urbana y sus inmuebles corresponden a los capturados entre 9 y 17 horas cuando el día es más largo (meses de febrero a junio) 45 y entre 10 y 16 horas cuando el día es más corto (meses de octubre a enero).

En el marco de sus usos en México desde los años 1930, en concreto a partir de la creación de la Compañía Mexicana de Aerofoto - primera empresa que se dedicará sistemáticamente al registro aéreo del territorio nacional bajo pedido gubernamental -, fueron fotografiadas en particular grandes obras de infraestructura, 


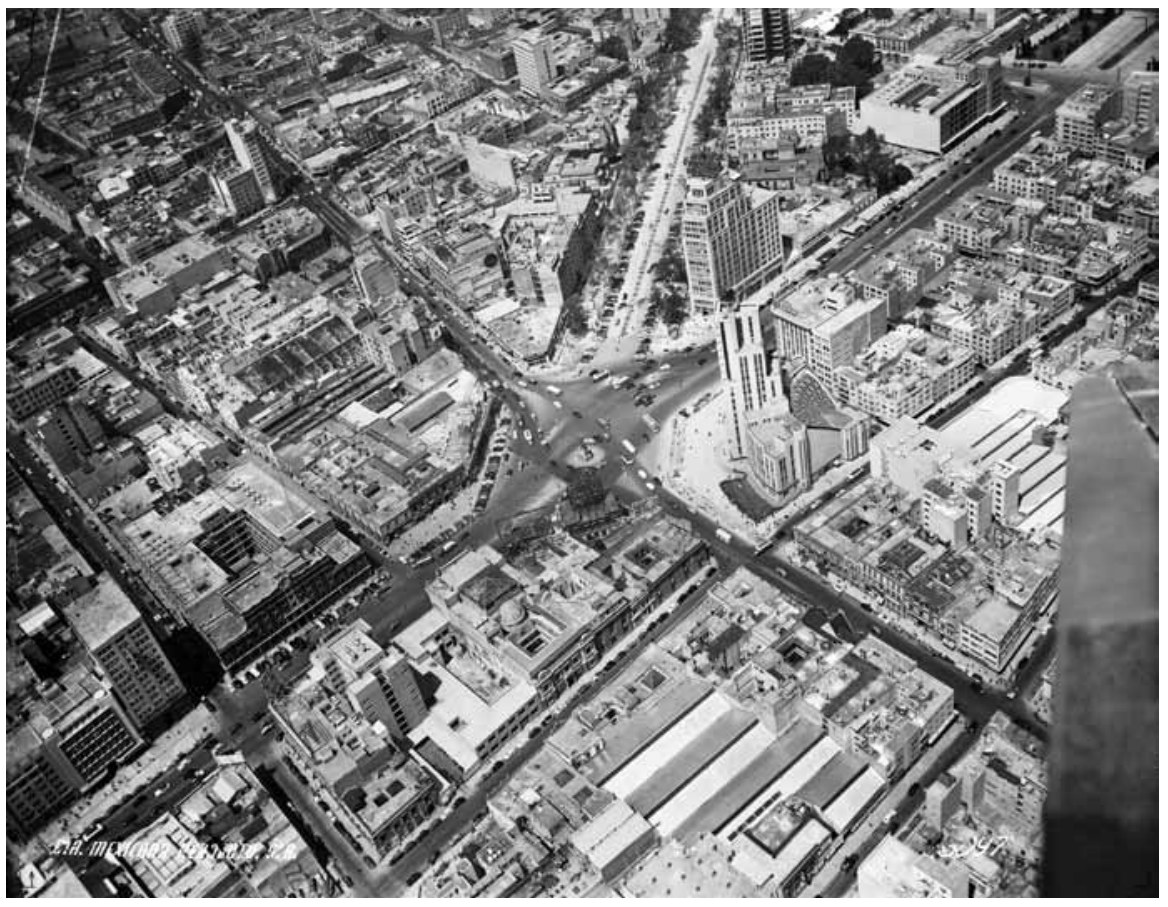

Imagen 3 - MXIM-2-3-4-5, Compañía Mexicana de Aerofoto, Ciudad de México, 6 de julio 1949. In: Fundación ICA, vuelo 6097

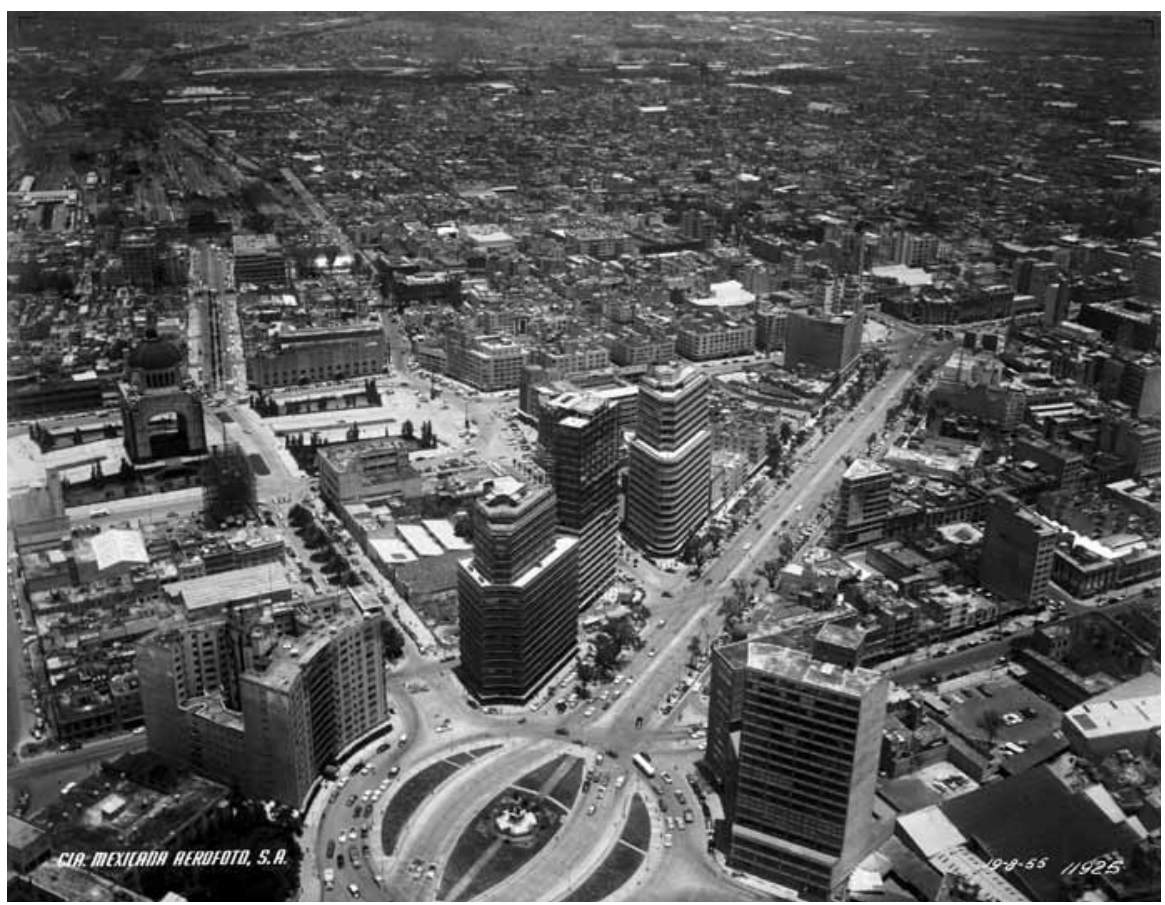

Imagen 4 - MxIM-2-3-5-1, Compañía Mexicana de Aerofoto, Ciudad de México, 19 de agosto 1955. In: Fundación ICA, vuelo 11925. de México, D.F. permaneciendo en ese lugar hasta el año de 1950. Véase <http:// www.sedena.gob.mx/index. php?id_art $=550>$ (consultado en mayo de 2010).

43. Como vimos líneas arriba, con el ejemplo de promoción que utilizó la revista Nuestra ciudad al ofrecer este tipo de imagen como regalo al suscriptor (véase cita respectiva a la nota 28 ). Desde luego este gusto por la llamada "vista de pájaro" viene de muy atrás, formado con la proliferación de numerosas vistas panorámicas de la ciudad que circularon en tiempos prefotográficos, construyendo en gran medida el conocimiento sobre la propia ciudad. Para una reflexión más amplia sobre las vistas de la ciudad véase el capítulo de Fernando Aguayo y Eulália Ribera Carbó en Fernando Aguayo y Lourdes Roca (inédito) Sobre el estado actual, destaca que en una somera búsqueda en línea sobre el tema lo primero que aparece son ofertas de registros de este tipo con fines de promoción y espectacularidad, hoy realizados incluso por zeppelines teledirigidos. Aunque por supuesto la promoción de la fotografía satelital ha venido a socavar de forma importante este medio y ha constituido un gran golpe para las empresas que todavía efectúan este trabajo, lo delicado sobre todo para fines de nuestras preocupaciones será asegurarnos de que el patrimonio fotográfico que han construido a lo largo de estas décadas se siga preservando.

44. Como son la Imagen 3 (6 jul. 1949), o la Imagen 4 (19 agosto 1955).

45. Como la Imagen 5, capturada al inicio de una tarde (feb. 1953), o bien la Imagen 6 , registrada hacia mediodía (3 dic. 1949).

46. "La ortofotografía (del griego Orthós: correcto, exacto) es una presentaci- 


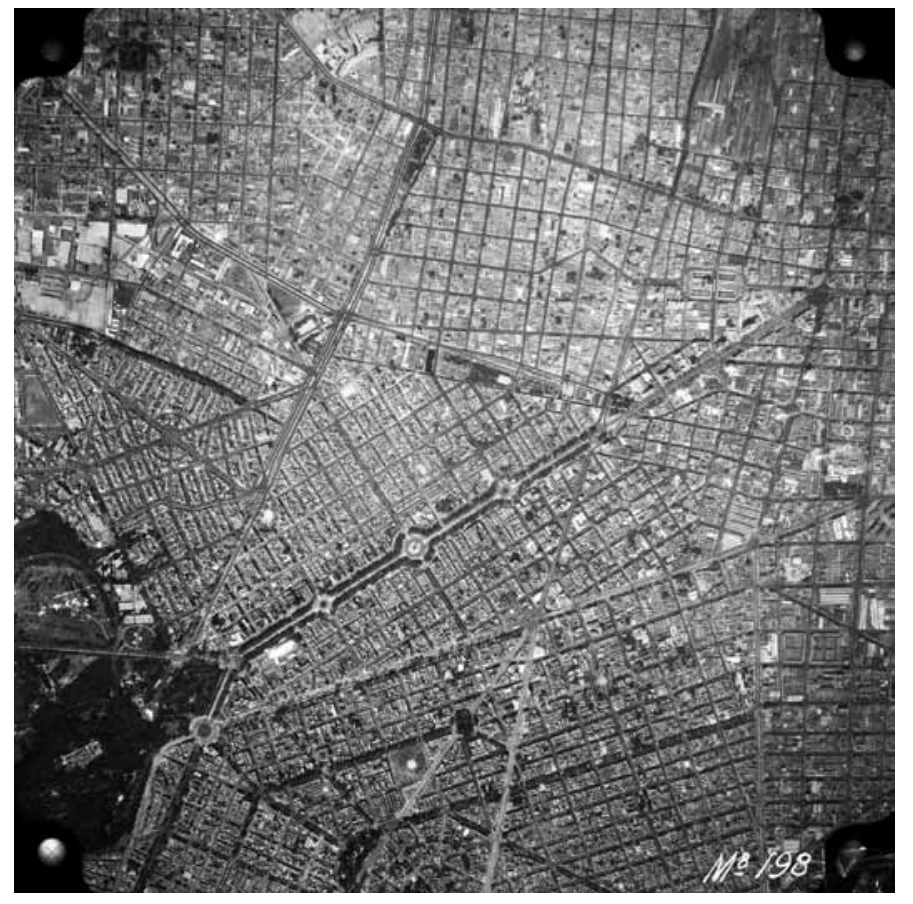

Imagen 5 - MxIM-2-3-5-4, Compañía Mexicana de Aerofoto, Ciudad de México, febrero 1953. In: Fundación ICA, vuelo 868/198.

Imagen 6 - MXIM-2-3-4-9, Compañía Mexicana de Aerofoto, Ciudad de México, 3 de diciembre de 1949. In: Fundación ICA, vuelo 418-AC2.

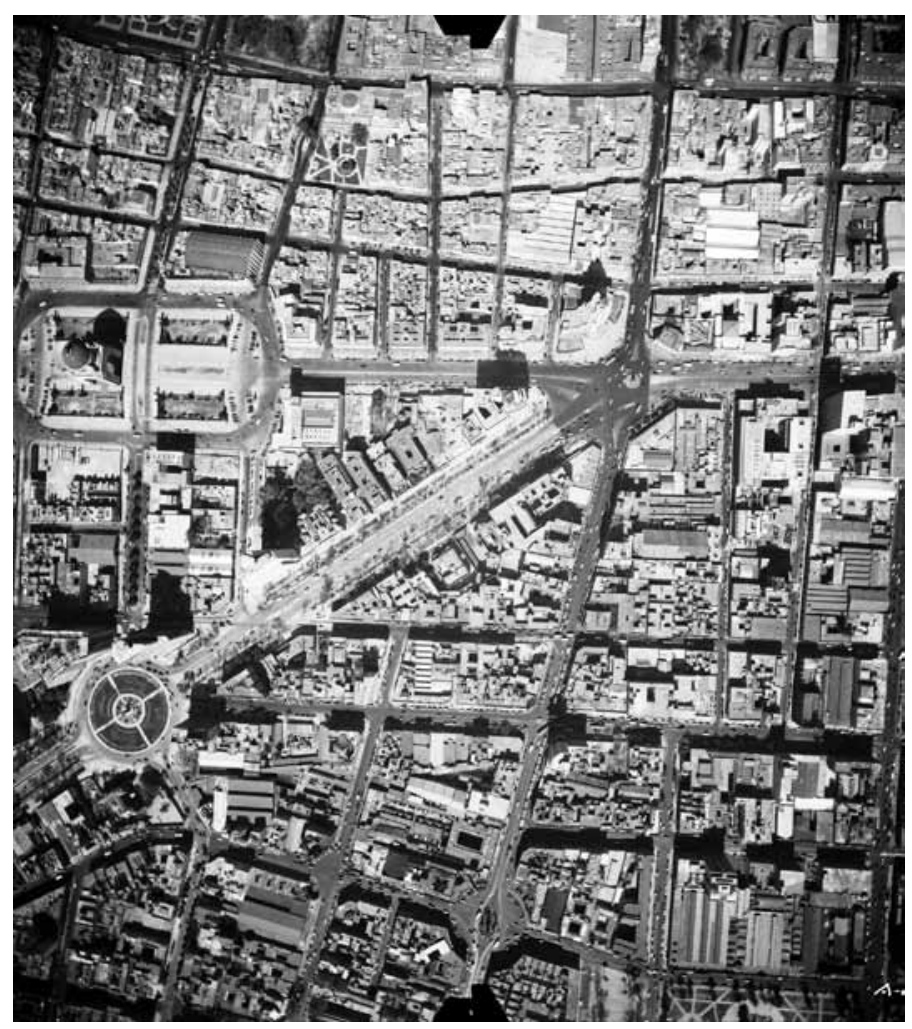


como presas, pero sobre todo se aplicaban a capturar tomas verticales con fines de reconocimiento del territorio y para la elaboración de los llamados "mosaicos" o grandes superficies de terreno reconstruidas a partir del traslape que permitían este tipo de fotografías, ya que las tomas se empalmaban en un $60 \%$ longitudinal, de manera consecutiva en cada línea, y hasta en un 30\% latitudinal o entre líneas paralelas voladas sobre el territorio, de manera que al armar los mosaicos aéreos se podía recuperar toda la parte de la foto que tenía el foco preciso, desechando los laterales, donde la óptica se altera. La construcción de mosaicos y ortofotos ${ }^{46}$ ha sido uno de los usos más convencionales de la fotografía aérea, que según la escala de vuelo podía implicar decenas o hasta miles de registros para un solo territorio, en relación proporcional: a mayor escala, más negativos, ya que eran tomas capturadas de forma más cercana a la superficie terrestre.

El resultado de todo este trabajo se ha conservado en su soporte original, negativo por negativo de acetato, la mayoría de $23 \times 23$ centímetros y en menor medida $18 \times 18$, ya sea cortado foto por foto o todavía en sus rollos originales, donde se puede seguir más fácilmente la trayectoria que llevó cada vuelo ${ }^{47}$. En el primer caso, cuando fueron cortados los negativos, si no hubo una numeración de los mismos lógicamente la rigurosidad en su orden peligra, por lo que se vuelve más compleja su consulta. En algunos casos fueron cortados con algún fin y luego vueltos a pegar, lo que hace muy complicada su conservación y ha implicado mucho trabajo de limpieza por los restos de pegamento que la cinta adhesiva ha dejado en los acetatos ${ }^{48}$.

De esta manera, acerca de la "selección y valoración" de los materiales en la conformación de este grupo documental constituido por los registros capturados desde el aire de la colección El Crucero de 'El Caballito' (Fondo LAIS del Acervo del Instituto Mora), preciso que estuvo sujeta a las posibilidades de localización de las fotografías aéreas de la glorieta en los tres archivos mencionados. La búsqueda implicó primero la revisión de todos los vuelos sobre la Ciudad de México que sobreviven de estas décadas (numerosos por año), fueran rollos enteros o recortados, para ubicar en su trayectoria de vuelo el punto en que volaron justo sobre la glorieta o lo más cerca posible; el resultado podía variar de hasta tres o cuatro vuelos anuales sobre la zona a ninguno. A su vez, considerando que los vuelos estaban destinados a capturar zonas amplias de la ciudad y a menudo toda ella, las líneas de trayectoria de la nave no siempre quedaban exactamente sobre la glorieta, por lo que tenemos fotografías donde sí quedó perfectamente en el centro de la imagen, pero también incluimos los registros que incluyen a la glorieta en algún de sus lados o esquinas. La cantidad de negativos por vuelo que incluye la captura de este espacio varía según la escala ${ }^{49}$ de vuelo utilizada que, salvo casos de excepción con menor o mayor rango, oscilaba entre 1:50.000 y 1:2.000; de manera que en la mayoría de casos los vuelos contenían de uno a tres registros cercanos a la glorieta, más o menos útiles según el grado de traslape que tuvieran entre ellos. Éste fue el criterio básico de selección y sólo se llegó a descartar algún negativo en que la glorieta estaba tan al borde de la imagen que las posibilidades de nitidez por la falta de foco eran casi nulas ${ }^{50}$. ón fotográfica de una zona de la superficie terrestre, en la que todos los elementos presentan la misma escala, libre de errores y deformaciones, con la misma validez de un plano cartográfico. Una ortofotografía se consigue mediante un conjunto de imágenes aéreas que han sido corregidas digitalmente para representar una proyección ortogonal sin efectos de perspectiva, y en la que por lo tanto es posible realizar mediciones exactas, al contrario que sobre una fotografía aérea simple, que siempre presentará deformaciones causadas por la perspectiva desde la cámara, la altura o la velocidad a la que se mueve la cámara.A este proceso de corrección digital se le llama ortorectificación. Por lo tanto, una ortofotografía (u ortofoto) combina las características de detalle de una fotografía aérea con las propiedades geométricas de un plano." Cf. <http:// es.wikipedia.org/wiki/Ortofoto $>$ (consulta: mayo 2010).

47. Para nuestra suerte, gran parte de los vuelos conservan su año de registro, a veces con todo y el día o por lo menos el mes. En pocas ocasiones esta información viene inscrita en el margen inferior, pero en diversa documentación asociada se conservaron las fechas de cada vuelo y hoy podemos recuperar esa información.Y en los laterales muchas veces contamos con información respectiva a la distancia focal, el nivel esférico, la hora de registro y el número de toma. Sin embargo, como esta información era registrada de forma automática por el equipo y por diferentes vías se me ha advertido que a menudo los medidores no funcionaban o no eran reiniciados, la información consignada por éstos no ha sido tomada en cuenta.

48. Curiosamente, para el caso del acervo de Fundación ICA (los otros conservan mayoritariamente los rollos 
completos), destaca una radical disminución en los cortes a partir de los años cincuenta, en que cada vez hay más rollos completos o los cortes ya sólo son en partes correspondientes a obras en particular. Esto nos indica que los rollos anteriores a los cincuenta han sido muy utilizados, pero no tanto como tales sino sus piezas sueltas, probablemente para armar mosaicos. Lamentablemente, hasta donde he podido indagar, no se conservan registros de estos usos que han implicado el recorte negativo por negativo de muchas y largas tiras de vuelos que podían rebasar hasta los dos mil registros.

49. Resultado de la relación entre distancia focal y altura de vuelo.

50. Más un solo caso en que el descarte fue por el estado físico de la pieza, ya que estos negativos han sido manipulados a menudo con diversos fines, insertando marcas con cinta adhesiva y los restos de pegamento o excepcionales roturas del acetato han ocasionado pérdida de información. Los archivos han hecho un trabajo muy loable de limpieza de estas piezas pero no puede faltar algún caso que ya no es posible restaurar.

51. Véase la obra litográfica de Casimiro Castro, de mediados del siglo XIX. Por ejemplo, Casimiro Castro (1866).

52. Véase Thierry Gervais (2001, p. 20).

53. Idem, p. 29-30.

54. Idem, p. 34.
De las imágenes y sus macro recortes de la ciudad

Pero pasemos a las áreas de "estructura y contenido" y "documentación asociada" de nuestra propuesta de documentación de acuerdo a la $\operatorname{lsad}(G)$, para adentrarnos más en lo que fue capturado en estas imágenes. La descripción nos ha permitido (y a la vez obligado) a poner atención en los detalles y a escudriñar la imagen lo más posible, sobre todo en el crucero y sus alrededores, considerando que este tipo de imágenes son adecuadas en particular para la visión más macro del espacio de estudio. De hecho, la vista desde el aire de este crucero es una de las primeras que se crearon de la Ciudad de México desde un globo ${ }^{51}$, junto con La Alameda o La Villa.

En aquel contexto y de la mano de Gervais, diríamos que empezaría el esparcimiento de una nueva forma de mirar el territorio, a través del "basculamiento de la mirada" hacia la toma perpendicular: con ella se funda una nueva iconografía que se volverá útil hasta que intermedie el avión, ya que los tiempos de pose y de secado eran demasiado largos, lo que dificultaba mucho la captura de los primeros registros desde el aire. Justo el uso militar mencionado que se le dará a este tipo de registros comienza a darle visos de utilidad: si el globo no se consideraba tan fiable por parte de los científicos, sí satisfacía del todo a los aficionados que se apasionaron con la navegación aérea a inicios del siglo XX52.

Conforme la mirada se perpendiculariza sobre la superficie terrestre, se va construyendo un nuevo punto de vista que permeará fuertemente la próxima producción fotográfica y sus vanguardias estéticas. Será justo esa perpendicularidad la que detone nuevas formas de percibir, admirar y reconocer el espacio terrestre y particularmente el urbano. Para el caso de Francia, Gervais anota cómo la proliferación de estas tomas incidirá directamente en la estética de varios fotógrafos de la prensa ilustrada ${ }^{53}$, que comenzarán a generar una gran producción de tomas picadas y verticales, no solo desde el aire sino también desde variados puntos de la nueva ciudad que se va verticalizando.

Para él, este proceso constituye incluso la evidencia de que, lejos del modelo cartográfico que de inicio se buscó seguir con los primeros registros capturados incluso por Nadar, la iconografía aérea encuentra finalmente una función, relacionada sobre todo con fines estéticos y de comercialización de las imágenes a través de la prensa ilustrada ${ }^{54}$. Sin embargo, y pese a procesos similares que pueden verse para el caso de México a partir de los años 1920 en revistas como las mencionadas, sin dejar de lado esas miradas, centraré la atención sobre todo en los espacios y momentos que a través de ella fueron capturados. Ahora bien, antes de adentrarnos en lo más local de nuestro espacio registrado desde el aire, retomaré algunas observaciones sobre la revisión de conjunto, que sugieren más preguntas que respuestas y seguramente pueden detonar futuras investigaciones sobre estos documentos.

Llama por ejemplo la atención que, particularmente en el caso del registro aéreo de la Ciudad de México, hasta los años 1950 las fotografías den 
cuenta de encargos de remodelación y modernización de la ciudad, donde el centro siempre es registrado, mientras después éste pierde protagonismo y ya son vuelos que captan más bien los diversos rumbos que conformarán la futura metrópoli - correspondientes a los antiguos pueblos, haciendas y ranchos de los alrededores conforme viven drásticas y aceleradas transformaciones -, entre los que destacan registros de Coyoacan, Churubusco, Colonia Roma, Hipódromo Condesa, La Villa, y un largo etcétera. Esta característica hace que en las primeras décadas sea mucho más sencillo ubicar el centro y localizar rápidamente cualquier punto de lo que antes fue la Ciudad de México, mientras en la segunda mitad del siglo XX resulta mucho más complicado que aparezca registrado el centro, y todavía más localizar cualquier punto de esa zona: si en las primeras décadas puedese encontrar no uno sino varios vuelos sobre la zona, para las siguientes décadas hay intervalos de dos y hasta seis años para verla de nuevo registrada. En cambio, aumentan los registros de zonas del sur y poniente de la ciudad, que es hacia donde crecieron rápidamente tanto la inversión de las élites como la transformación urbana. Además, los vuelos son cada vez más altos, lo que es resultado de una mayor precisión en los equipos pero también de mayores limitaciones presupuestales que ya no permiten vuelos con tal cantidad de registros (conforme creció la ciudad se requerían más y más) y, en cambio, obligan a vuelos mucho más acotados espacialmente y a menor escala, lo que reduce la cantidad de líneas de registro y tomas de negativos, y con ello la cantidad de material (rollos) y el tiempo requerido (sobre todo el combustible) para el trabajo.

Con un criterio básico de organización de toda la colección en tres grandes grupos documentales (registros desde el aire, registros desde altura y registros desde calle), organizamos el primero que aquí nos atañe (registros desde el aire) en subgrupos cronológicos que corresponden a décadas ${ }^{55}$. Las principales preguntas de investigación han partido, por un lado, de las propias transformaciones del espacio en la glorieta y su entorno inmediato; por el otro, de las construcciones fotográficas que se elaboraron en diversos periodos acerca de este retratado crucero de la ciudad y sus posibles intenciones, a las que habrá que agregar las capturadas desde diversas alturas y desde pie de calle. Es decir, interesa analizar desde dónde y hacia dónde ha sido registrado, abarcando qué espacios, privilegiando qué motivos y destacando qué aspectos, lo que será cabalmente posible hasta tener todo el conjunto fotográfico documentado, por lo que las preguntas en este sentido quedan pendientes para una siguiente entrega de la investigación.

Las fotografías aéreas del crucero de El Caballito (1930 a 1970): de lugar de confluencia a espacio de expulsión

La propuesta fue indagar primero que nada acerca de las construcciones fotográficas a partir de las miradas macro o de conjunto que permiten las fotografías aéreas (como después lo será con los paisajes urbanos) que capturaron
55. De ahí el código de referencia con el que documentamos la colección, construido de la siguiente forma: México мx, Instituto Mora ıм, El Caballito (colección 2), Registros desde el aire (grupo documental 3), Década correspondiente (subgrupo 3 para los años treinta, 4 para los años cuarenta y así consecutivamente hasta el 8 para los años ochenta), más un consecutivo por fotografía. Ejemplo: Imagen 7. 
56. Definida por el interés de iniciar esta investigación con el análisis de la mirada fotográfica construida desde el aire, dejando (como ya se ha dicho) para una próxima etapa los niveles de registro desde diversas alturas y desde la calle. La treintena de imágenes escogidas incluyó tanto fotografías cenitales como oblicuas de las cinco décadas contempladas, para tener acceso a una visión de conjunto acerca de este medio siglo, tanto de manera vertical como sesgada sobre el terreno.

57. Cf. Federico Fernández Christlieb (2000b, p. 99-109). algún detalle o acontecimiento concretos desde diversas alturas y a nivel de calle, de este espacio que fue rápidamente urbanizado en el marco de la planificación y el crecimiento de la ciudad hacia el poniente y surponiente. Recapitulemos primero algunos puntos relativos a estas imágenes y sus contextos de producción para anotar algunas conclusiones preliminares.

El grupo de imágenes para la investigación abarca un siglo de tomas fotográficas de este espacio, desde algunos de los primeros registros del crucero en la década de 1870 hasta 1979, año en que la escultura es retirada de este lugar para trasladarla frente al Palacio de Minería. Estas imágenes proceden de varios archivos y conforman el corpus visual general. La presente selección de una treintena de fotografías aéreas, acotada al periodo de 1930 a 197056, partió de la década en que la práctica de la fotografía aérea se generaliza, capturando seguido este crucero ya con características completamente urbanas, y llega a la última década del marco temporal más amplio, en que el monumento es trasladado a una plaza céntrica de la ciudad (1979), unas cuadras al oriente del crucero estudiado.

Este primer avance de investigación se centró en el trabajo con los registros desde el aire, es decir, con el nivel más macro posible, a partir de esta selección de imágenes constituida por tres decenas de fotografías correspondientes a las cinco décadas mencionadas. La gran mayoría fue registrada por la Compañía Mexicana de Aerofoto, que en la década de 1930 se inicia de manera sistemática en la captura de fotografía aérea, originada con la práctica gubernamental de registrar el territorio nacional con fines de su levantamiento, reconocimiento y control. Tiempo después será adquirida por la principal constructora del país, Ingenieros Civiles Asociados (ICA), por lo que en el acervo conformado podemos encontrar las principales obras de construcción realizadas por esta empresa, capturadas de forma muy completa desde el aire. Los registros nunca han tenido un crédito personal de fotógrafo sino empresarial, adjudicándose la autoría a la Compañía Mexicana de Aerofoto a lo largo de todas estas décadas. Un par de registros de las últimas décadas (1960-1970) corresponden a Struck Fotogramétrica Internacional, otra empresa mucho más joven que conserva registros desde los sesenta, fundada por un ex integrante de la primera y que de muchas maneras derivó de las experiencias habidas en aquélla.

El caso particular de estudio ha sido este espacio enclavado en el centro de la Ciudad de México. Tiene su origen en la creación del Paseo Nuevo - Paseo de Bucareli en 1775, con el entronque que dibujó la confluencia de éste y la Calzada del Calvario; y adquiere la forma que lo proyectará como uno de los principales cruceros de la ciudad y referente urbano por más de siglo y medio al instalársele una escultura ecuestre de Carlos IV en el centro, en 1852. Desde entonces, destaca la creación de otro Paseo trascendental en la vida de la ciudad, el de la Reforma, en su origen Paseo de la Emperatriz, que partirá justo del crucero adornado con la estatua de El Caballito hacia el surponiente, para unir la ciudad con Chapultepec. De ahí la que Fernández Christlieb tildaría de "ciudad bipolar" por esta ubicación de los poderes en dos extremos ${ }^{57}$, que promoverá la percepción de un nuevo centro más al poniente, o por lo menos desdibujará el centro tradicional que había existido por siglos, proyecto largamente acariciado tanto 
por el fugaz imperio como por las élites porfirianas. Poco después, promovido también por Porfirio Díaz, se concebirá y proyectará un Palacio Legislativo en el costado poniente del crucero, que inicia sus obras en 1910 para quedar truncadas con el movimiento revolucionario ${ }^{58}$ y la paralización del flujo de capitales para este tipo de construcciones. De esta manera, el crucero de El Caballito, enmarcado por el paréntesis del que debió ser un eje imperial casi terminado en la segunda mitad del XIX, que uniría el Palacio Legislativo con el Palacio Nacional y el Zócalo de la ciudad, queda destinado a convertirse en el centro geográfico de la Ciudad de México ${ }^{59}$, inmerso en la tremenda marejada que será el siglo XX - un centro que, por más que ha habido intentos de consolidar por parte de las élites inversionistas y urbanistas, nunca llegó a ser.

Pero precisemos, a propósito de este marco moderno en que se desenvuelve este espacio, que consideramos lo moderno como algo que se busca de manera permanente; entendemos que cada momento ha tenido su distintivo moderno, por lo que tampoco podemos hablar de una sola idea de modernidad urbana $^{60}$, sino que ésta la tiene cada periodo de la historia llamada "moderna" y por tanto sus características son distintas según la época y latitud de que hablemos. El neoclasicismo tuvo su dosis de moderno y de él traemos a colación para este estudio sobre todo la búsqueda de perspectivas urbanísticas y la concepción del bulevar como una amplia arteria arbolada y con glorietas que respondería en particular a las necesidades de ventilación urbana, de ahí el Paseo Nuevo o Paseo de Bucareli trazado en la segunda mitad del siglo XVIII.

Pero con las ideas haussmannianas y los referentes porfirianos parisinos que imperarían desde mediados del siglo XIX, vendrían nuevas concepciones de lo moderno, sobre todo afrancesadas, como después con la revolución y el nacionalismo serían éstas desbancadas en busca de lo nacional, para seguir con la mira en lo cosmopolita e internacional, con el faro de la vanguardia arquitectónica y urbanística ya no europea, sino concebida en Chicago y Nueva York. Y con ella llegamos a lo que Fernández Christlieb tildó hace tiempo como "la ciudad del automóvil"bl, donde ya hay la convicción de que el estilo neocolonial resulta una contradicción y sobre todo la incipiente admiración por los Estados Unidos que se manifiesta desde los años veinte con la apropiación de las teorías funcionalistas, queda definitivamente arraigada en los años cuarenta. Esta década de los rascacielos estilo internacional del que la glorieta es un ejemplo con el edificio El Moro (1946) será seguida por más edificios de altura y grandes ejes viales con pasos a desnivel, como los que resultan del entubamiento de ríos y canales para tender largas alfombras de asfalto al servicio del parque vehicular que aumenta y aumenta vertiginosamente desde los cincuenta, siguiendo los pasos de ciudades como Los Ángeles, donde no se puede vivir sin automóvil.

Como símbolo del permanente rodar que se va imponiendo en la ciudad, sirva recordar que la gran llanta del anuncio de Goodrich que remataba el edificio Corcuera en la esquina surponiente de la glorieta estuvo girando día y noche por casi dos décadas, lo que permanece en la memoria de muchos capitalinos a la fecha. El automóvil había llegado para quedarse y expandir su territorio hasta el último rincón de la ciudad. Desde entonces se convirtió
58. Del cascarón férreo que se alcanza a construir, tiempo después se recuperará solamente el cuerpo central para convertirlo en el Monumento a la Revolución (1933-1938).

59. Entre los ejemplos que podemos encontrar de este espacio como detonador de incrementos en el valor de uso de suelo del poniente de la ciudad, destaca un anuncio de la colonia La Verónica, que recupera Katzman, en el que los fraccionadores promueven el rumbo destacando que está tan cerca del centro de la ciudad (que ellos ubican visualmente en El Caballito a través de un dibujo donde una mano con compás traza el círculo que lo demuestra), como lo está el Palacio Nacional. Cf. Israel Katzman (1993, p. 38).

60. Porque "por modernidad habría que entender el carácter peculiar de la forma histórica de totalización civilizatoria que comienza a prevalecer en la sociedad europea en el siglo XVI"; cf. Bolívar Echeverría (2005, p. 144).

61. Cf. Federico Fernández Christlieb (2000a, p. 54-57). 
62. Cf. Marshall Berman (2000, p. 89-90). rápidamente en símbolo de ascenso social en México y la administración de Ernesto P. Uruchurtu, el llamado regente de hierro, acabará de consolidarlo: entre el largo periodo de 1952 a 1964 en que gobernará la ciudad aumentan 346 kilómetros las vialidades que la atraviesan. Una futura metrópoli que alcanza rápidamente los tres millones de habitantes para 1950, seguirá incrementando su población hasta llegar a los quince millones para el cierre del periodo que aquí nos atañe, años en que se atizará todavía más la expansión de la urbe y su parque vehicular, con la construcción de los ejes viales que promovió Carlos Hank, durante el gobierno de López Portillo.

Por todas las implicaciones que puede tener, pareciera increíble que la transformación de un espacio urbano se realice en aras de construir una vialidad recta donde no la hay o bien obtener una perspectiva de un edificio o monumento donde no estaba, pero esa ha sido una práctica generalizada en las construcciones y reconstrucciones de las diversas nuevas ciudades que se van inventando e ideando según el contexto socioeconómico y político. En unos casos ha significado destruir viviendas, iglesias, conventos, edificios públicos; en muchos desalojar a personas, expropiar terrenos y construcciones de particulares, etc., siempre en aras de darle nuevas y reformadas caras a la ciudad, según estilos, modas, principios y sobre todo intereses de quienes tienen poder de decisión sobre estos espacios, todo ello constituyendo "lo moderno" del momento que se trate. Numerosos ejemplos en nuestra ciudad en distintos periodos - como la apertura de las calles y avenidas Cinco de Mayo (ampliada en 1905), 20 de Noviembre (1935) y Reforma Norte (1964) -, son muestra de estos procesos, el último de los cuales atañe al presente estudio.

Insisto en que concibo aquí lo moderno en lo urbano como lo propuso Berman, como el cambio permanente, el anhelo perpetuo de renovación tanto en las formas de vida personal como social62. Los intereses de la clase dominante están creados justo en ese cambio constante que emerge de la crisis y el caos, en que catástrofes como las inundaciones o los temblores, comunes en esta ciudad, son justo el detonador de grandes oportunidades lucrativas de desarrollo y mayor renovación. Para ser permanentemente modernos hemos aprendido a desear el cambio por el cambio, buscarlo y generarlo en todas nuestras acciones y pensamientos, deleitarnos con la movilidad, esperar con ansias la renovación de todos y cada uno de los aspectos de nuestras vidas.

En sintonía con este ambiente socioeconómico, este crucero ha sido remodelado en cuantiosas ocasiones a lo largo de más de siglo y medio que tiene de haberse concebido como espacio urbano; su imagen debía transmitir ese anhelo de cambio permanente que caracteriza a lo eternamente moderno y de ahí proyectarse como un referente urbano cuyas representaciones se siguen reproduciendo tanto en su versión virreinal como en su cara cosmopolita e internacional. En el ámbito de las transformaciones, considero importante identificar los principales cambios que se dieron en la glorieta, como remodelaciones en la base de la escultura de El Caballito, construcción de nuevos edificios, apertura de nuevas calles, nueva traza de la glorieta según cambios de vialidad, usos sociales de ese espacio urbano, para plantear algunas conclusiones que sirvan 
de antesala a la siguiente etapa de investigación con el conjunto fotográfico capturado desde otros niveles, como edificios aledaños de varias alturas, o desde la propia calle.

Hemos avanzado por lo pronto con las fotografías registradas desde el aire. A grandes rasgos enumero los principales cambios que éstas permiten ver de la glorieta como tal y sus alrededores, para tenerlos más precisos en el seguimiento del análisis de este espacio urbano, sus transformaciones y sus construcciones fotográficas. Estos cambios se han conocido no sólo con el trabajo de observación y descripción de las imágenes capturadas, sino sobre todo de cotejo y comparación entre ellas.

1. La glorieta misma, cuyo centro casi geométrico fue durante décadas el pedestal con la escultura de El Caballito, fue ampliada en diversos momentos y transformada en un crucero de forma más bien elíptica, conforme fueron aumentando el tránsito vehicular y las arterias que desembocaban en él63. Con varios cambios en el ajardinado de su base, primero cuadrada, luego circular y finalmente elíptica, acabó quedando totalmente aislada de cualquier uso peatonal por el aumento en cantidad y densidad de circulación vial a su alrededor, de la mano del propio diseño que

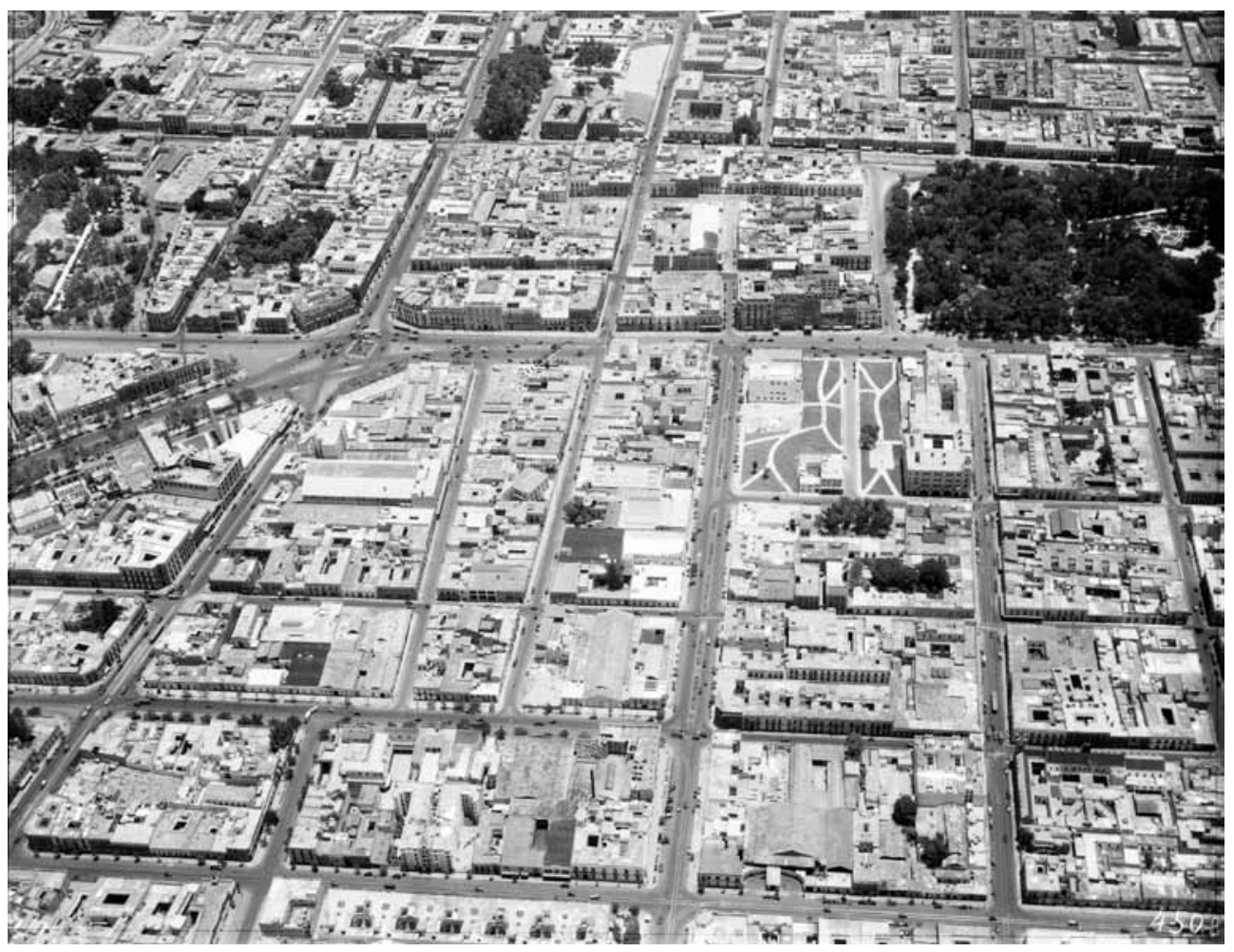

Imagen 7 - MxiM-2-3-3-2, Compañía Mexicana de Aerofoto, Ciudad de México, 1932. In: Compañía Mexicana de Aerofoto, $450 b$.

Annals of Museu Paulista. v. 19. n.1. July.-Dec. 2011.

63. Imagen 7 (1932), Imagen 8 (1958) e Imagen 9 (ca. 1964). 


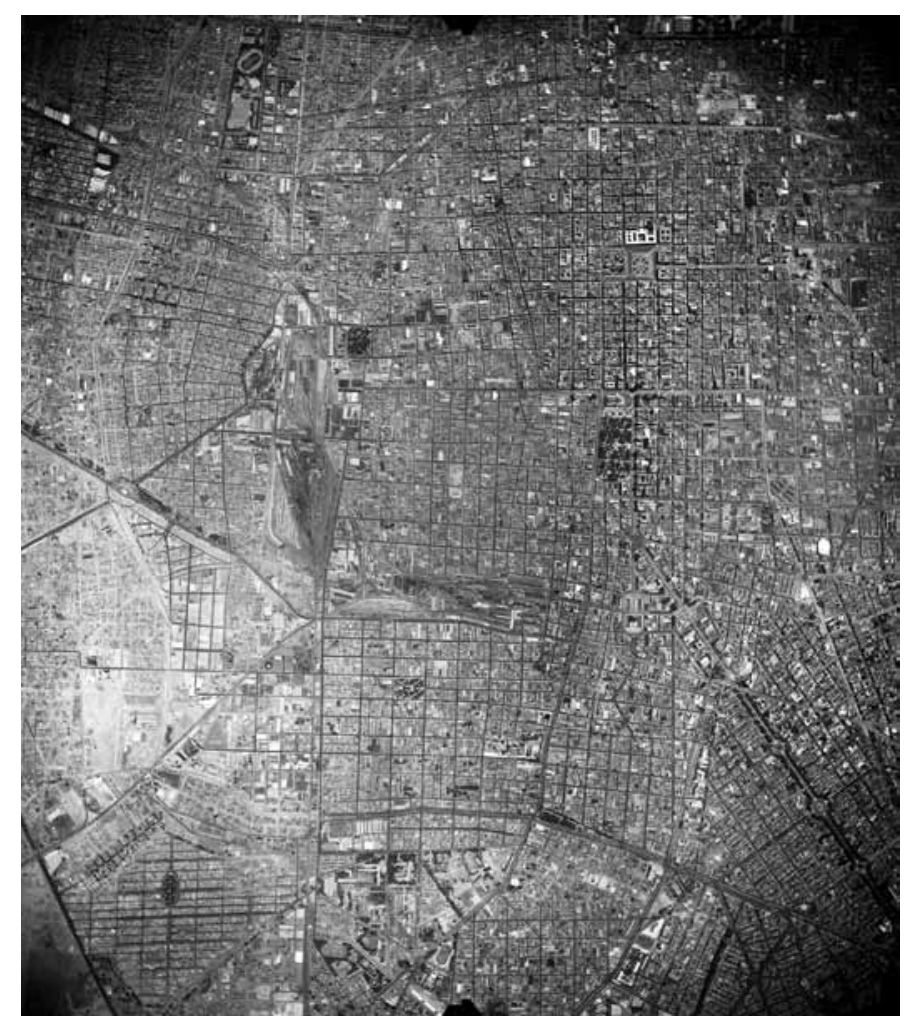

Imagen 8 - MXIM-2-3-5-6, Compañía Mexicana de Aerofoto, Ciudad de México, 1958. In: Fundación ICA, vuelo 553/2.

Imagen 9 - MXIM-2-3-6-1, Compañía Mexicana de Aerofoto, Ciudad de México, ca. 1964. In: Compañía Mexicana de Aerofoto, s/r.

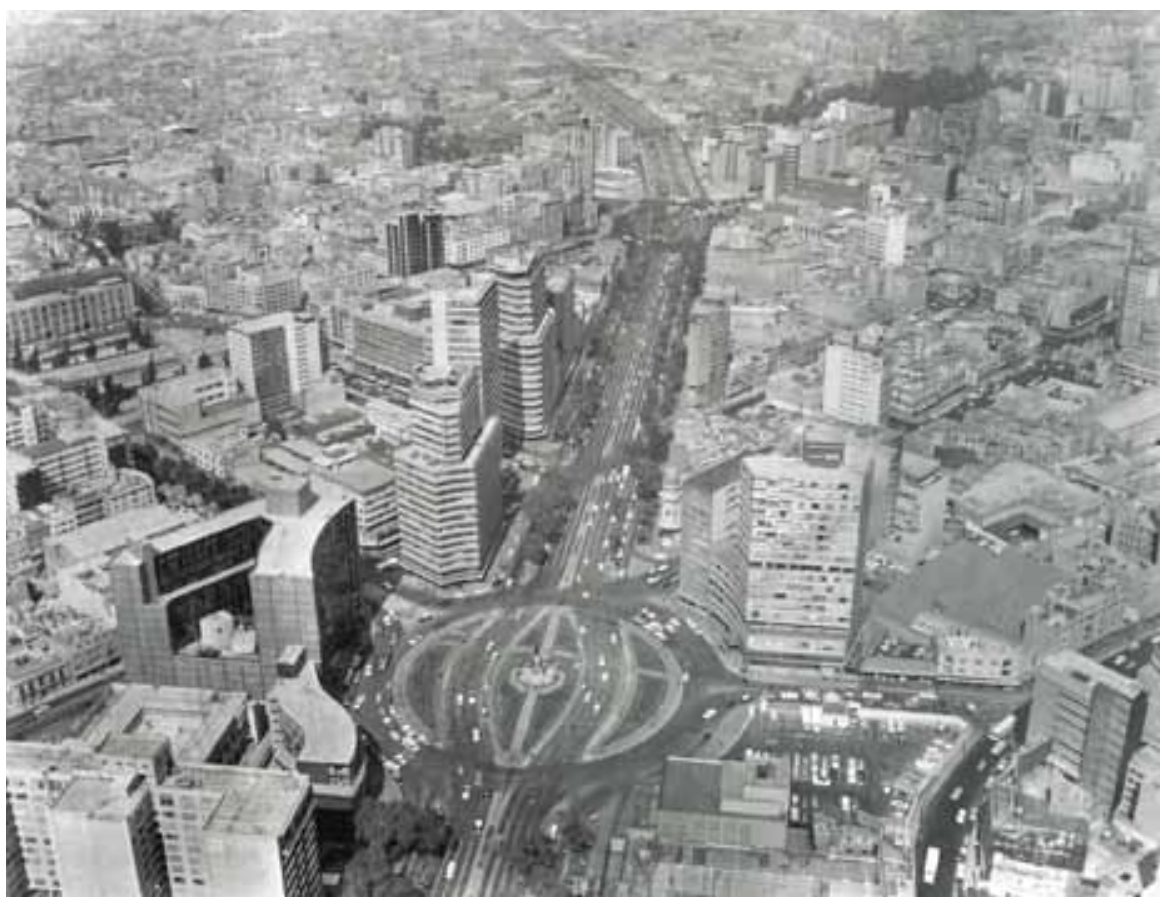


se le fue otorgando en este sentido, cada vez con un patrón de circulación más rígido. De hecho, cuando en los años setenta se proyectan los ejes viales para una nueva trama reticular de circulación en todos los sentidos (norte, sur, este y oeste), hasta el propio Caballito acaba estorbando a la vialidad; por esa y otras razones es removido en mayo de 1979 del crucero para instalarse poco después en la Plaza de Minería o Plaza Tolsá.

2. En el entorno inmediato, caracterizado durante décadas por una altura de dos pisos y edificios de los siglos XVIII y XIX, destaca una radical y acelerada transformación encabezada por la Lotería Nacional justo en la segunda mitad de los años 1930, con la construcción del edificio El Moro ${ }^{64}$, considerado el segundo de altura en la ciudad después del edificio La Nacional (1932) frente al Palacio de Bellas Artes ${ }^{65}$. Enseguida, más edificios de igual y mayor altura, hasta sobrepasar los cien metros con la Torre Prisma (1970), construida también por la Lotería Nacional y sus necesidades de expansión, y alcanzar hasta ahora los más de treinta niveles de la actual Torre del Caballito (1988).

3. De hecho, uno de los aportes más visibles de la fotografía aérea es el que permiten precisamente las sombras que proyectan las
64. Una vez destruido el antiguo edificio de la Lotería, que había sido la casa del diputado Tomás de la Torre y Mier, en la esquina norponiente de la glorieta.

65. Imagen 10 (ca. 1940) e Imagen 11 (11 jun. 1949). El Moro estrictamente fue el tercero, porque el segundo fue el Edificio Corcuera, ubicado en contra esquina con él. Sin embargo, como éste resultó dañado con el temblor de 1957 y poco después fue derrumbado, en general ya no es considerado. Investigaciones como ésta permiten recuperar la existencia de una edificación como el Corcuera, que formó parte de la imagen 'moderna' que se buscó construir del crucero en los años cuarenta y cincuenta, -donde duró casi veinte años-, como permitirá mostrar sobre todo el estudio del siguiente corpus visual sobre esta glorieta.

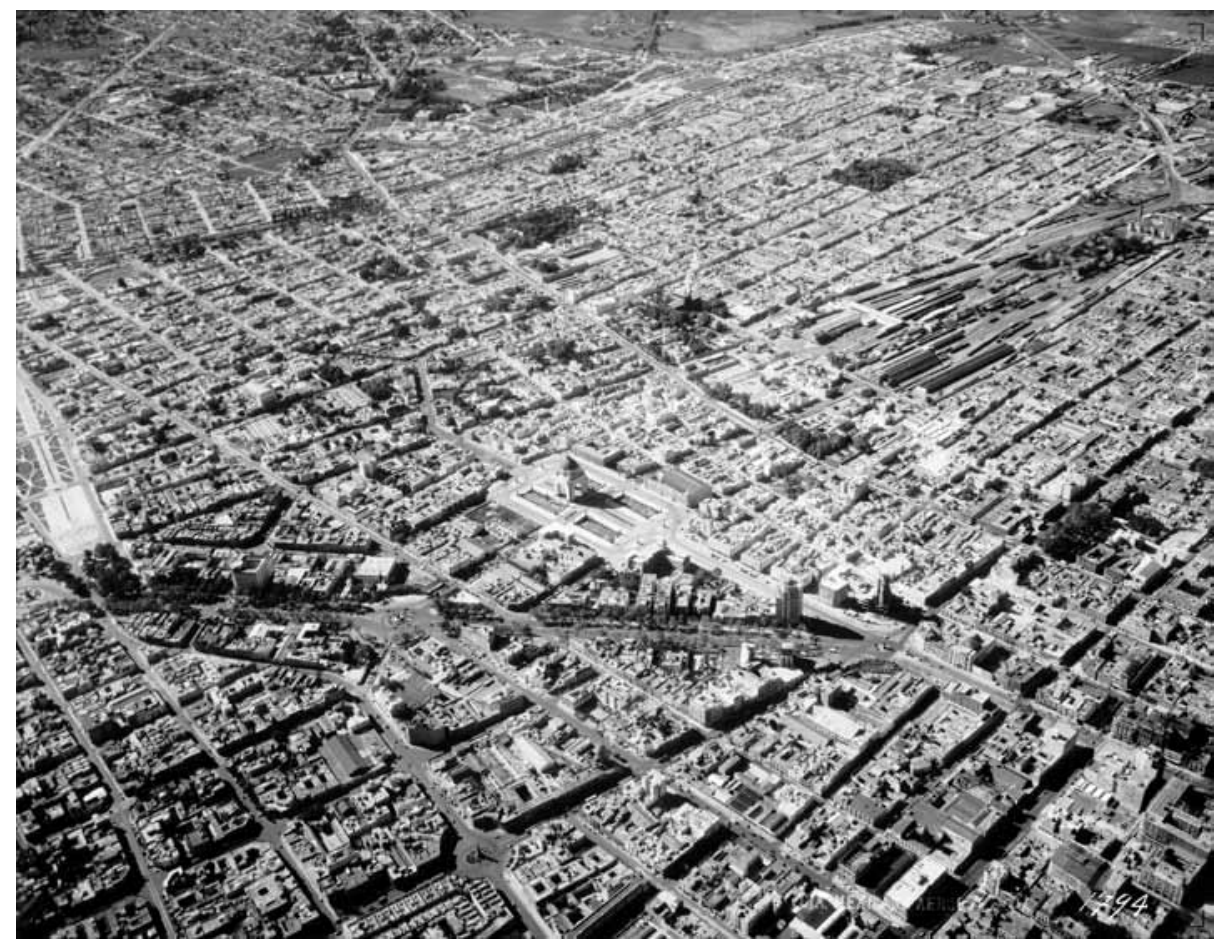

Imagen 10 - MXIM-2-3-4-1, Compañía Mexicana de Aerofoto, Ciudad de México, ca. 1940. In: Fundación ICA, vuelo 1794. 
66. Imagen 6 e Imagen 12

67. Ver Imagen 13 (1957) frente a Imagen 14 (1936).

68.Ver Imagen 8 (1958) frente a Imagen 15 (1934).

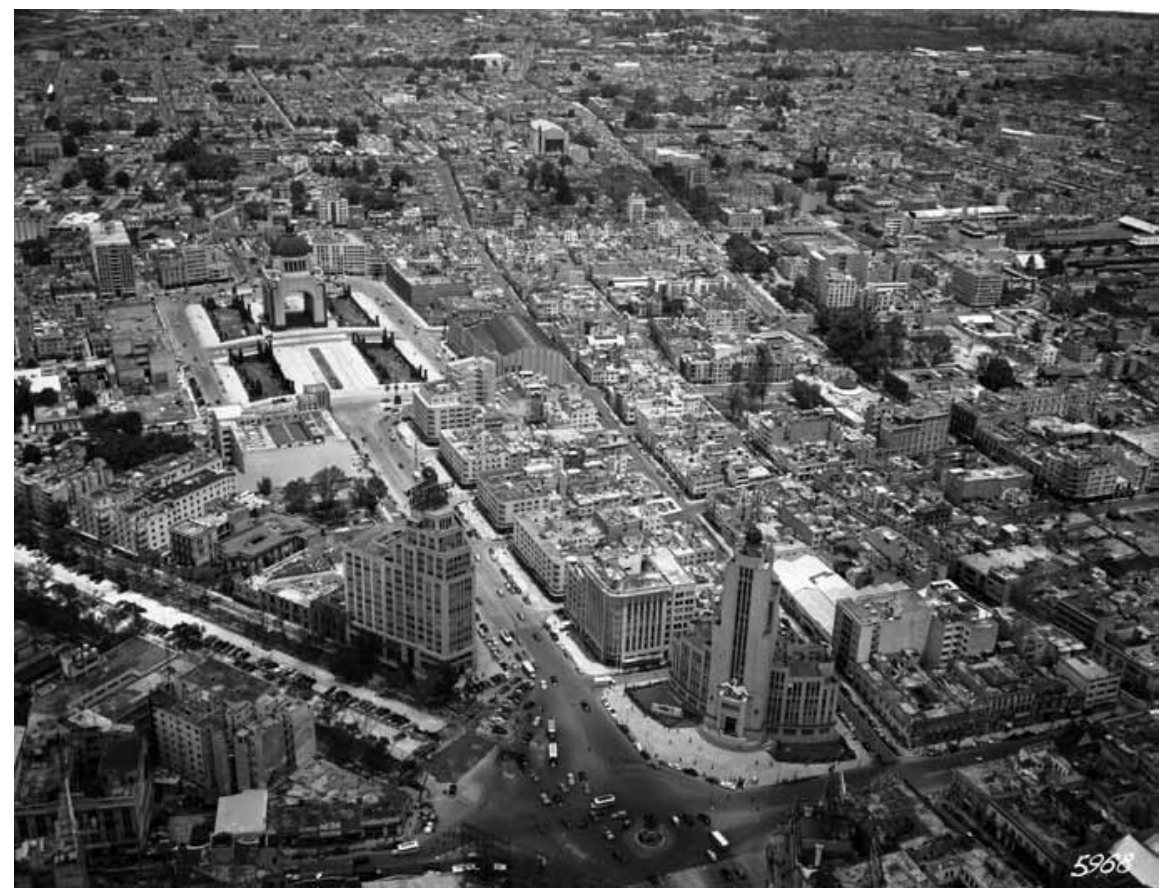

Imagen 11 - MxIM-2-3-4-4, Compañía Mexicana de Aerofoto, Ciudad de México, 11 de junio 1949. In: Fundación ICA, vuelo 5968.

diversas alturas: haciendo un corte transversal en el tiempo con registros exclusivamente invernales, cuando las sombras son más largas - al grado de simular hasta fotografías caladas por el intenso contraste que su color negro genera con el resto de texturas ${ }^{66}$-, podemos observar claramente esta verticalidad en aumento y cómo entre las fotografías, por ejemplo de los años treinta y los cincuenta, esta zona de la ciudad aumenta hasta alcanzar más de cien metros con la altura de sus edificios ${ }^{67}$. Es decir, es pertinente una descripción que se detiene también a ver las diferentes texturas justo para detectar la procedencia de esos negros que no son más que largas sombras generadas por la altura de los edificios, o bien las que revelan áreas verdes que por supuesto en este intervalo de tiempo también se reducen ${ }^{68}$. Podemos ver concretamente cómo desaparece el Tívoli del Eliseo tan pronto inician las obras por parte de la Lotería Nacional del que será el Edificio El Moro - comparar la Imagen 2 (1932), cuya imagen ocupa en gran medida el Tívoli del Eliseo con todas sus áreas verdes y diversas instalaciones, con la Imagen 14 (1936), en que ya se ven los cimientos del mencionado edificio y el Tívoli ha desaparecido por completo para que en su lugar emerian varias nuevas cuadras y apenas reste una esquina del amplio 


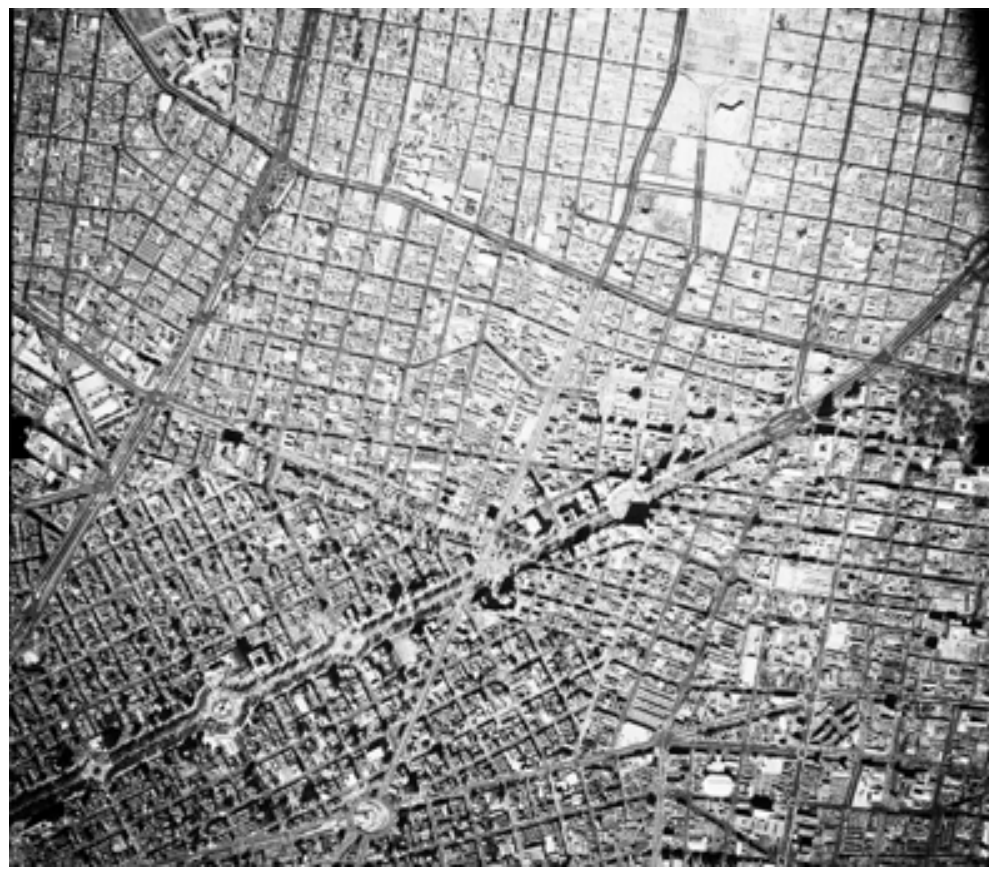

Imagen 12 - MXIM-2-3-7-1, Compañía Mexicana de Aerofoto, Ciudad de México, 18 de marzo 1972. In: Fundación ICA, vuelo 2346/1

Imagen 13 - MXIM 2-3-5-5, Compañía Mexicana de Aerofoto, Ciudad de México, 1958. In: Fundación ICA, vuelo 593D-1.

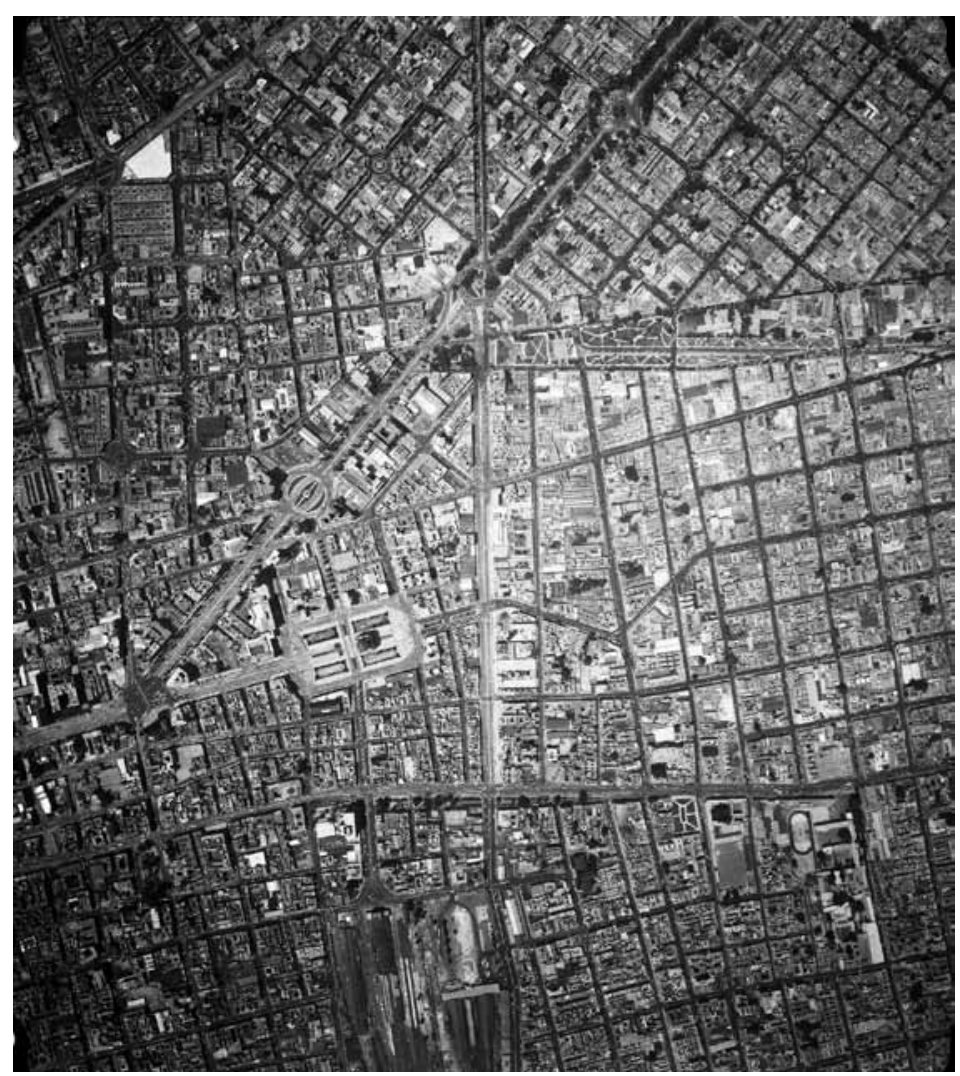




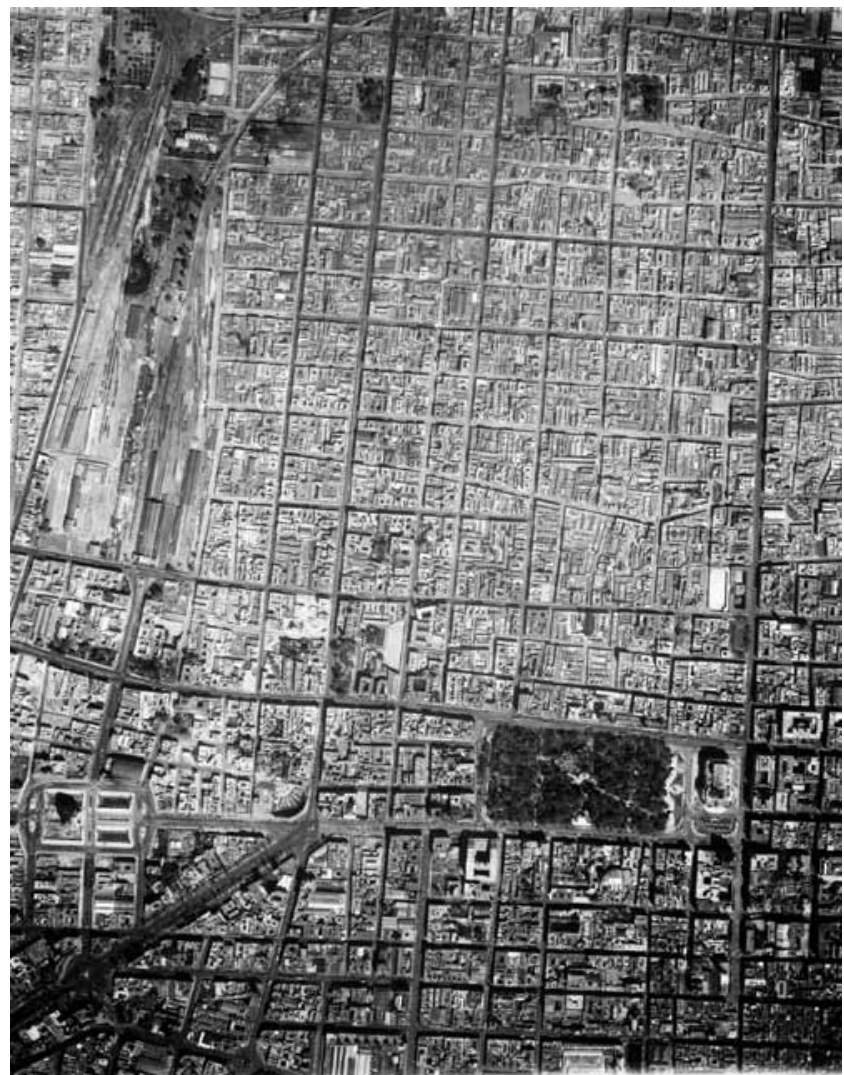

Imagen 14 - MxIM-2-3-3-4, Compañía Mexicana de Aerofoto, Ciudad de México, 1936. In: Fundación ICA, vuelo $91 / 86$.
Imagen 15 - MxIM-2-3-3-5, Compañía Mexicana de Aerofoto, Ciudad de México, 1934. In: Fundación ICA, vuelo 89-90/39.

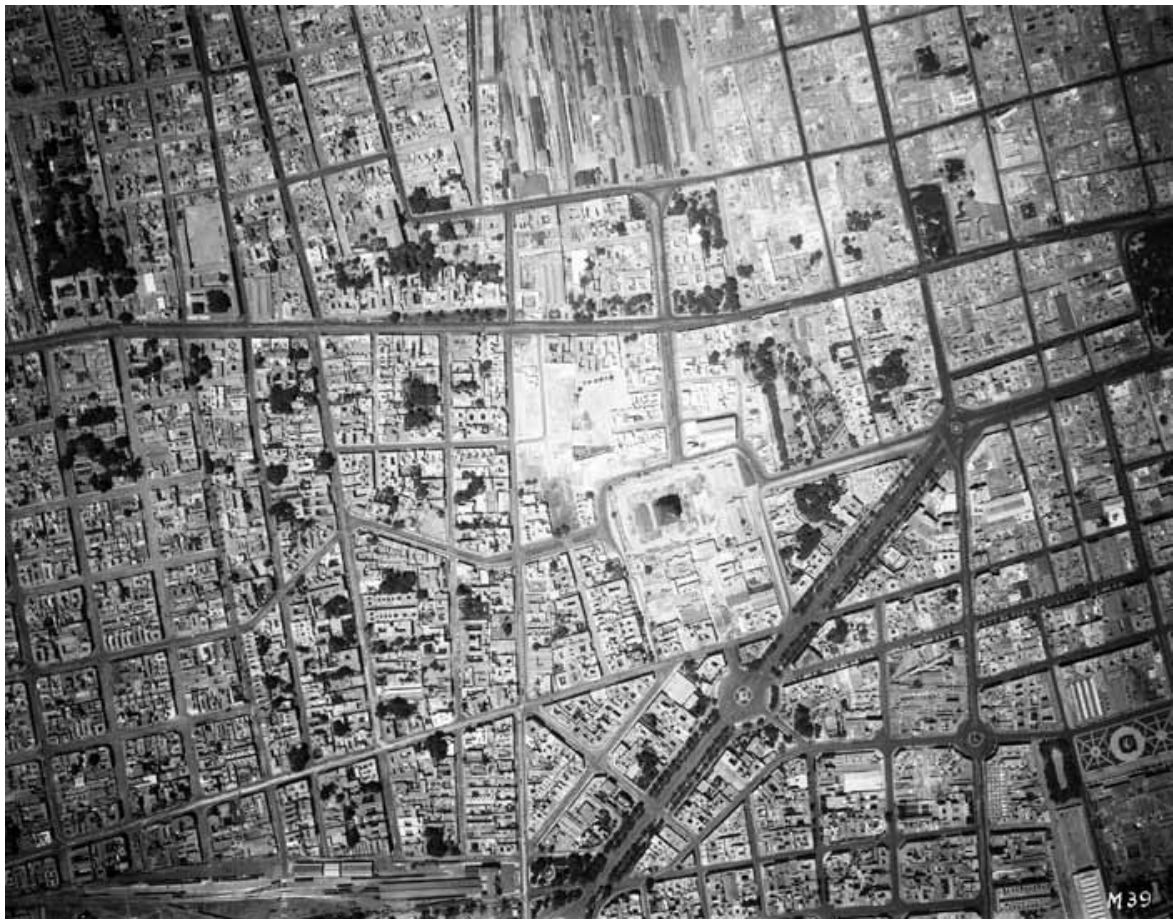

Anais do Museu Paulista.v. 19.n.2. jul.-dez. 2011. 
parque como simple jardín interior del antiguo palacio de Buenavista $(1805)^{69}$.

4. La transformación de las diversas calles, avenidas, paseos y después arterias viales que en ella confluyen o de ella parten: desde el Paseo de la Reforma, cuya traza determinará en adelante la forma de crecer de la ciudad hacia el surponiente y poniente, hasta la apertura de Reforma Norte, que cambiará radicalmente la fisonomía del crucero y su nororiente para siempre: ${ }^{70}$ ahora sí, como cantó Chava Flores, "Vino la Reforma a Peralvillo"7l. Así, de confluencia de paseos para el solaz y esparcimiento de los habitantes en el siglo XIX e inicios del XX, pasamos rápidamente a la presencia de carruajes y después autos Ford T que fueron imperando; creación y ampliación de asfaltados, camellones y banquetas para la circulación peatonal; y con el tiempo su nueva reducción hasta la mínima expresión, en aras de aumentar el espacio vial para un parque vehicular que no ha dejado de crecer por ya cerca de un siglo72. De hecho, a partir de los años 1940
69. Como puede verse claramente en el gran detalle que la Imagen 6 permite. El edifício es obra también del valenciano Manuel Tolsá y hoy Museo Nacional de San Carlos.

70. Imagen 9 (ca. 1964).

71. Acesible en <http://ww w.youtube.com/watch?v $=$ rbmWiSFdiMQ $>$.

72. Imagen 16 (1963) e Imagen 17 (8 feb. 1978).

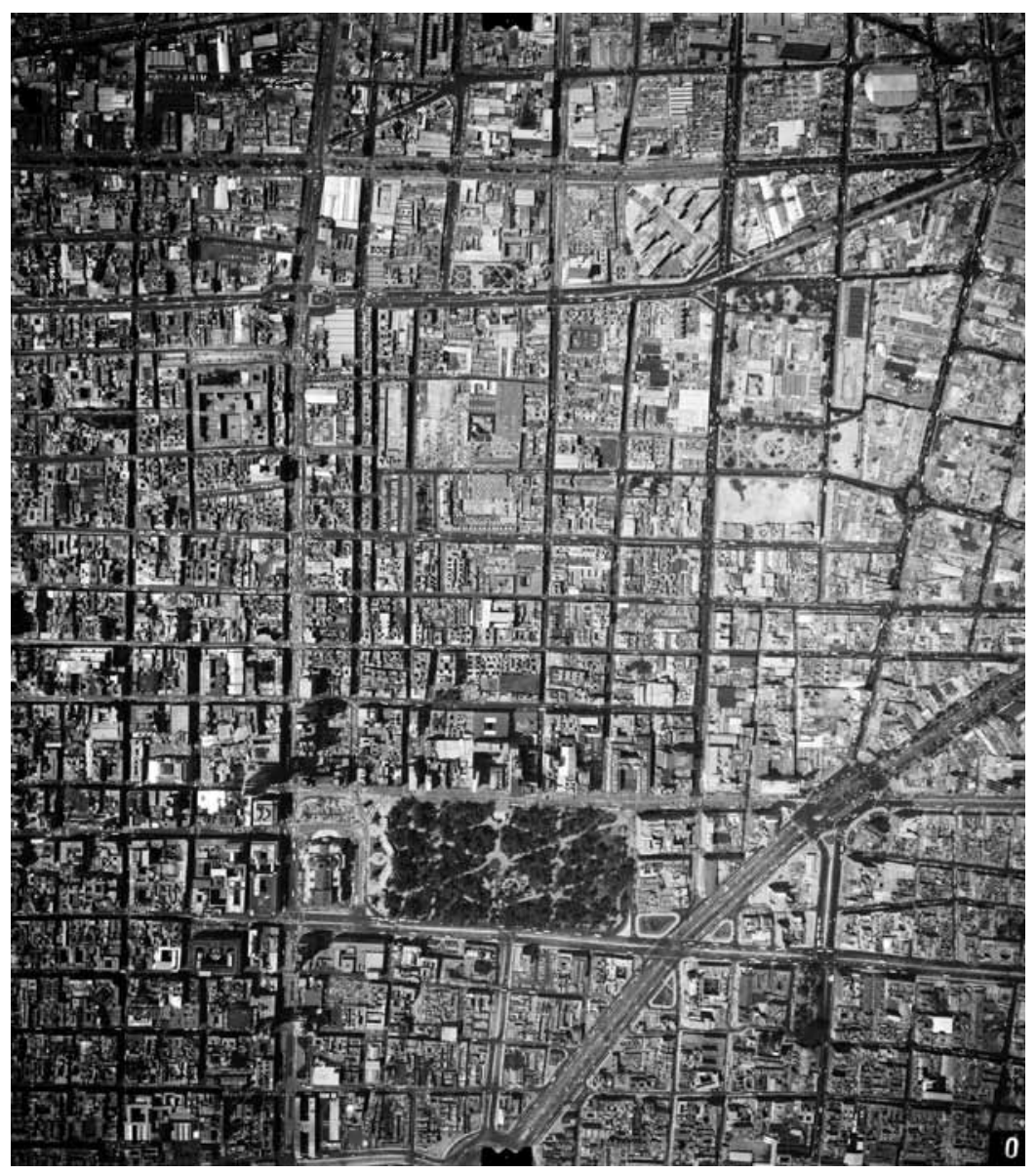

Imagen 16 - MxiM-2-3-6-4, Compañía Mexicana de Aerofoto, Ciudad de México, 1963. In: Fundación ICA, vuelo 1821. 


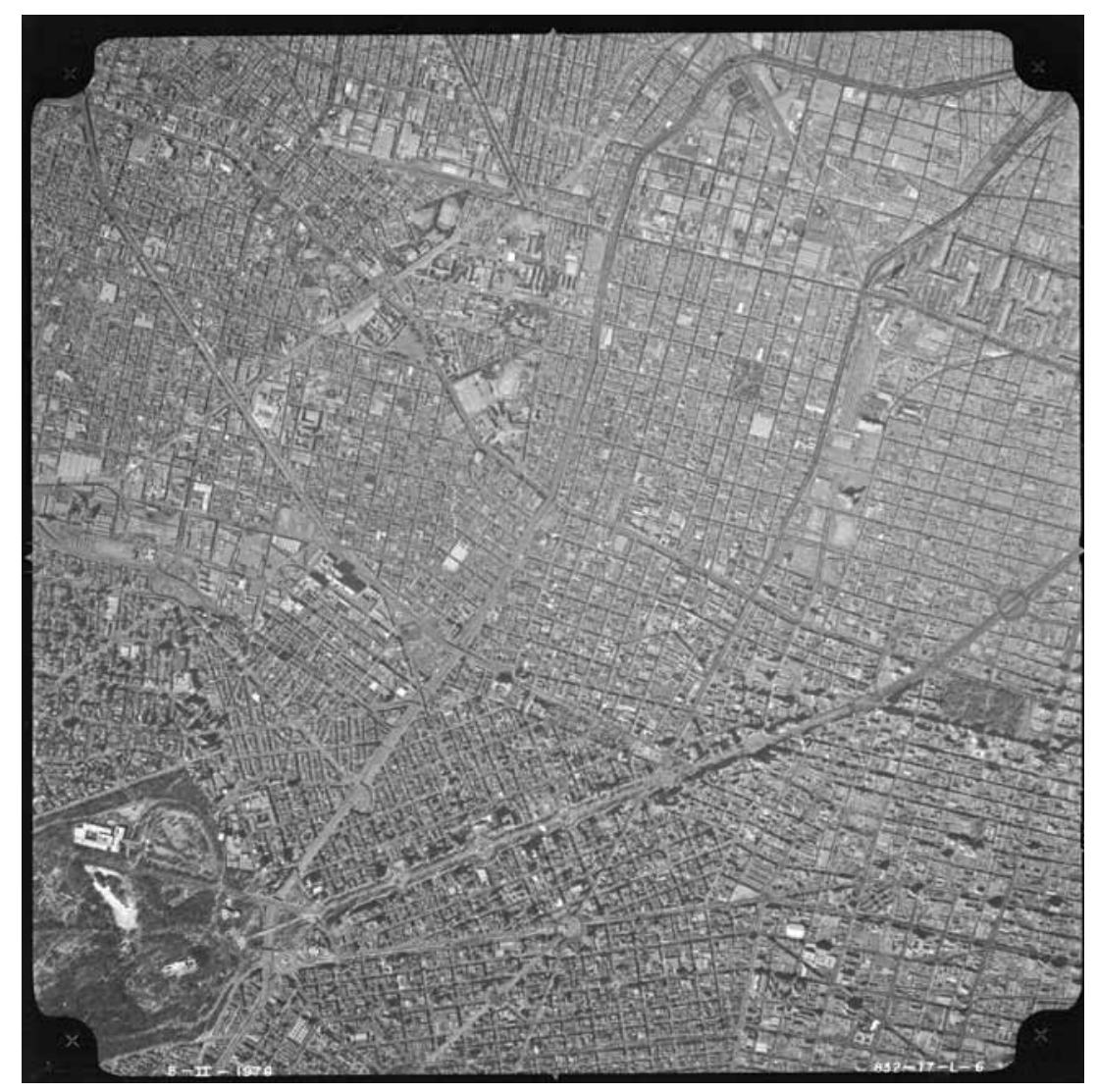

Imagen 17 - MXIM-2-3-7-2, Struck Fotogramétrica Internacional, Ciudad de México, 8 de febrero 1978. In: Struck Fotogramétrica Internacional, 1978.
73. Imagen 18 (1936), Imagen 3 (6 jul. 1949), Imagen 5 (feb. 1953) e Imagen 16 (1963).

74. No es gratuito que la práctica tradicional de protestar y marchar desde El Caballito hasta el Zócalo acabara mudando en una elipsis más amplia que partiría del Monumento a la Revolución hacia el mismo destino; en el crucero ya era imposible pararse y mucho menos congregarse. la glorieta y su entorno comienzan a verse con más y más coches estacionados, en particular en su esquina suroriente, donde arranca la avenida Juárez, y en ambos lados del Paseo de la Reforma.

5. De esta manera, una glorieta que permitía la confluencia y congregación de la población desde varias latitudes de la ciudad, alrededor de cuya estatua era común ver transitar o incluso posar a habitantes de diversos niveles socioeconómicos, todavía hasta los años 1920, se convierte paulatinamente en un nodo expulsor de gente, cuyo movimiento centrípeto acaba escupiendo literalmente a todo transeúnte hacia los extremos ${ }^{73}$, con un monumento cada vez menos accesible al peatón y, cada vez más, convertido en polo de exclusión ${ }^{74}$. Con todo ly que las fotografías aéreas permiten un análisis de carácter más bien macro), podemos ver detalles como éste que escaparía más fácilmente a las fotografías a nivel de calle, donde siempre se ven peatones pero resulta más complicado poder ver las formas de transitar por un espacio con estas características.

En este aspecto podríamos establecer un paralelismo entre el nivel micro del crucero y el macro de la ciudad, con la forma de transitarla hasta los 


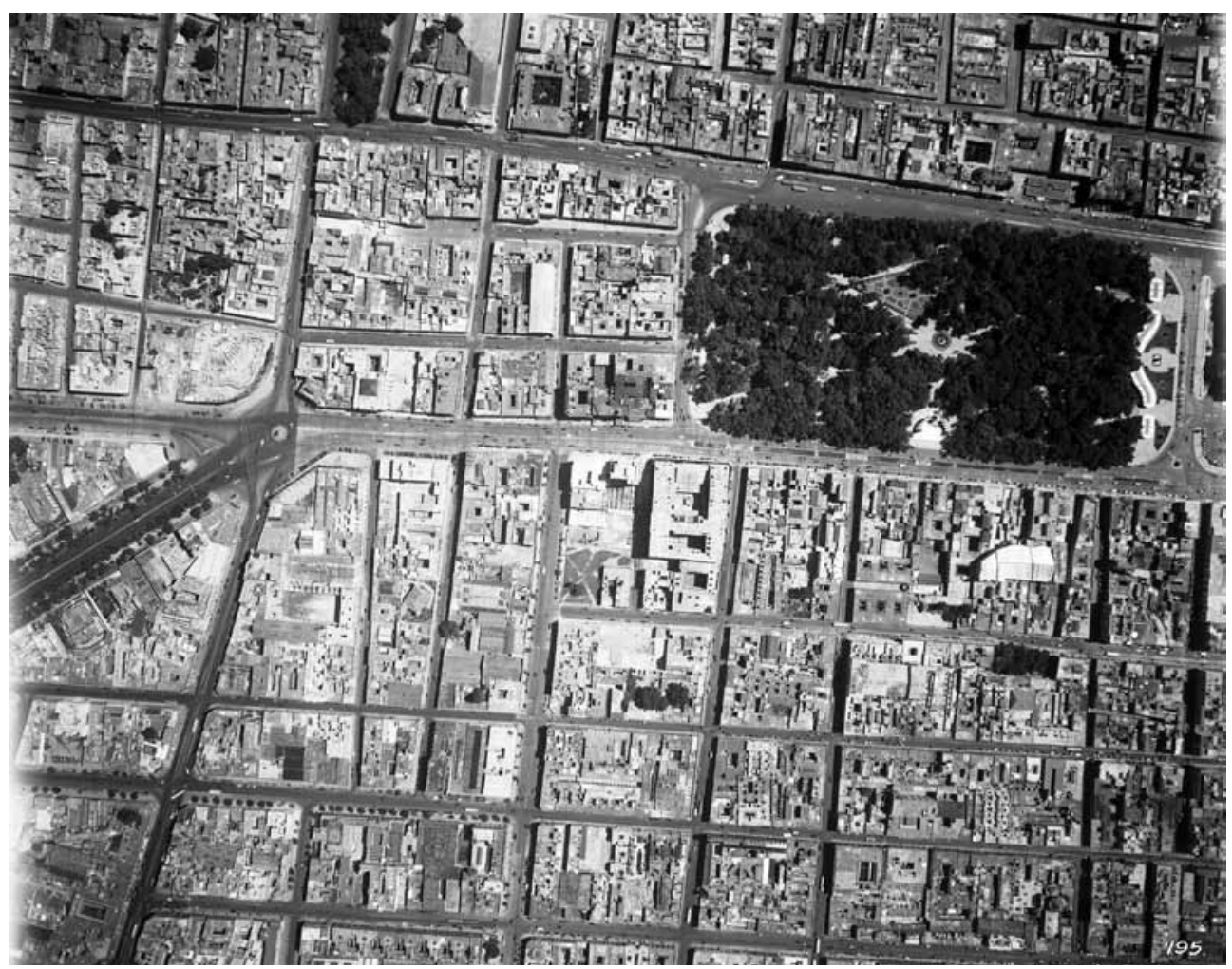

75. Como gustaba decir el arquitecto Mario Pani. Véase Graciela De Garay et al. (2001).

Imagen 18 - Mxim-2-3-3-6, Compañía Mexicana de Aerofoto, Ciudad de México, 1936. In: Fundación ICA, vuelo 92/195.

años 1950, siempre con el centro como principal imán en todos los aspectos comercial, político, cultural, etc. -, práctica que comienza a dislocarse en esa década hacia una movilidad multifocal rumbo a numerosos centros, con el crecimiento desbordado que ya no tendría límite en toda la siguiente mitad del siglo XX, en que la ciudad se convertiría en una gran cantidad de ciudades fusionadas en una metrópoli.

Al grado que, en esas siguientes décadas, los bordes se volverían a su vez focos nodales a ser retratados (Neza, Tlalpan, Santa Fe, Xochimilco, Naucalpan, Chalco, Ecatepec, entre otros), lo que reflejan los propios registros aéreos, que como hemos venido diciendo para las décadas 1960-1970 ya evidencian mayor preocupación por otros espacios urbanos: la ciudad ya no es sólo el ahora centro, sino que pasan a predominar los vuelos sobre las zonas sur y poniente, particularmente y en concordancia con los procesos de transformación que venimos describiendo. La concepción de Ciudad Satélite en los años 1950 y de la ciudad olímpica con toda su arquitectura deportiva en los sesenta, entre otras, son detonadores de este crecimiento acelerado de la ciudad "dentro de la ciudad y fuera de la ciudad"75, pero también la proliferación primero de unidades habitacionales y después de centros comerciales hacia los polos de la metrópoli, como el Multifamiliar Miguel Alemán (1949), el Multifamiliar Benito Juárez (1952),

Annals of Museu Paulista. v. 19. n.1. July.-Dec. 2011. 
76. Todavía hoy podemos escuchar entre las generaciones que practicaron la ciudad entre los años 19301970 , que constituía un punto de encuentro: "Nos vemos en el Caballito".

77. No sobra agregar el promedio de diez minutos que hoy día requiere un peatón para cruzarlo de un extremo a otro, lo que implica atravesar un mínimo de tres semáforos que otorgan mucho mayores intervalos de tiempo a la circulación vehicular que a la peatonal.

78. Quizá y en gran medida, entre otros factores, por ese afán de la nueva arquitectura y urbanidad imaginadas por las clases media y alta, como diría Fernández Christlieb, que busca una forma de vivir retraída hacia el interior de la vivienda, construyendo la idea tan arraigada en ciertos sectores de la ciudad de que la actividad de las calles es "algo impropio para las familias modernas”. Cf. Federico Fernández Christlieb, apud Eulalia Ribera Carbó (2004, p. 90). el Conjunto Urbano Nonoalco Tlatelolco (1964), Plaza Universidad (1970) y Centro Comercial Perisur (1979), por mencionar algunos.

Así pues, según permiten analizar las tomas capturadas desde el aire, la característica de espacio de confluencia que tuvo de inicio la glorieta de El Caballito, como cualquier crucero - con un referente de encuentro y reunión encarnado en la estatua ecuestre y múltiples escenas de convivencia de transeúntes y habitantes ${ }^{76}$-, se irá difuminando a lo largo del siglo XX. Su importancia como uno de los principales referentes de la urbe fue tal que marcó pautas urbanas de lo que es una ciudad en efervescencia; su acelerada transformación responde a fuertes intereses por el control del espacio urbano de la ciudad. En escasas décadas, el privilegio a la circulación vehicular y los intereses por adueñarse de los predios circundantes para sacarle literalmente metros al aire, primero por parte de la Lotería Nacional y después del propio gobierno federal, entre muchos particulares también, definirán finalmente el destino de la glorieta en su diseño urbano y las construcciones de su entorno, hasta convertirse en uno de los puntos de mayor altura con los treinta y cuatro niveles que tiene el edificio de construcción más reciente, la Torre del Caballito (1988), así como en uno de los principales nodos antipeatonales de la ciudad; ${ }_{7}^{77}$ es decir, uno de tantos espacios de expulsión social que la caracterizan desde hace medio siglo.

Por un largo periodo que abarca siglos constituyó uno de los principales polos de esparcimiento de la ciudad, primero por sus condiciones naturales de terreno cenagoso, y después por diversos inmuebles e instalaciones de sus alrededores que podían hacer el deleite de los habitantes, como La Plaza del Paseo o el Tívoli del Eliseo en el siglo XIX, y la Alberca Pane o incluso el teatro El Caballito en el XX, el cual sobrevivió hasta la apertura de Reforma Norte; y también fue lugar de encuentro y de expresión del que se pueden recuperar numerosas manifestaciones tanto de júbilo como de inconformidad de la población, lo que veremos sobre todo cuando trabajemos con las fotografías capturadas a pie de calle. Pero hacia mediados del siglo XX la glorieta cada vez tendrá menos ese carácter que resulta de la confluencia y convivencia social78, hasta perder casi cualquier rastro de actividad humana desde luego en su centro, e incluso en su perímetro, poco a poco reducido a espacio de tránsito entre grandes propiedades públicas y particulares. De hecho, si acudimos a ella veremos que con dificultades uno puede siquiera detenerse a observar porque el constante fluir te obliga a avanzar de banqueta en banqueta, incluso bajo el ojo inquisidor de algún vigilante que parece preguntarse qué haces deambulando por la glorieta, si no es para cruzarla de un lado a otro. En pocas palabras, en escaso medio siglo ha devenido un lugar en el que se supone que no se debe estar: el fluir es permanente y nada ni nadie se debe detener ahí.

Para concluir, valga señalar que si uno de los primeros vuelos efectuados por la Compañía Mexicana de Aerofoto, correspondiente a 1932, dio pie a la construcción del pequeño corpus visual aquí abordado, fue también por constituir uno de los últimos registros donde todavía se aprecia una ciudad de perfil bajo (uno a dos niveles), con importantes áreas verdes por doquier, ciertamente a punto de cambiar en escasos años con la introducción como hemos visto de las 
propuestas de planificación y urbanismo funcionalistas procedentes sobre todo de Estados Unidos: "¡Chicago en México!". Las ideas de ciudad y urbanismo que se fueron concibiendo en estas décadas podrían extraerse cual calcas de este grupo de imágenes, donde se corrobora la eficacia lograda en el "ordenamiento" de la ciudad desde la perspectiva de las élites, con criterios que privilegiaron el mundo vehicular por encima del que construye la población a pie, así como el de la inversión inmobiliaria y la verticalidad pese al peligro sísmico, siempre en aras de incrementar el valor del suelo mandándolo literalmente a las alturas.

Resta mucho por analizar. Las miradas a pie de calle permitirán observar otros aspectos no contemplados y corroborar varios de los aquí apuntados, posiblemente sugiriendo otras hipótesis y otras explicaciones a la transformación general de este microespacio cuya diversidad de imágenes ha representado tantas veces a la ciudad moderna, ya sea del siglo XVIII, XIX o XX, para seguirse reproduciendo hoy constantemente como la cara cosmopolita e internacional de la ciudad; una ciudad que, en concordancia con la fuerza centrípeta de la que hemos hablado, ha desatendido mucho su sino en aras de construir una imagen de supuesta modernidad, de la que el crucero ha sigo insignia desde sus inicios. Quizá la segregación esté ineludiblemente implícita en todo aquello que se tilde de moderno.

Finalmente, aspiramos a que este trabajo detone más búsqueda de conocimientos sobre fotografía y espacios urbanos, sobre todo en lo que respecta a las imágenes de la ciudad como fuentes de investigación social: cómo ha sido vista y ha interesado que sea observada la ciudad desde numerosas miradas que la han capturado con la lente a lo largo de siglo y medio, y desde los diversos tiros, ángulos y ópticas posibles, para desentrañar por ejemplo cuáles han sido las construcciones fotográficas aéreas que se han elaborado sobre la ciudad en distintos momentos, pero que también han hecho ciudad al mostrarnos cómo es y cómo se ha querido que sea vista de acuerdo a los múltiples intereses en turno.

\section{REFERENCIAS}

\section{ARCHIVOS}

Compañía Mexicana de Aerofoto.

Fundación ICA (Ingenieros Civiles Asociados).

Mapoteca Orozco y Berra, Servicio de Información Agroalimentaria y Pesquera (Sagarpa).

Struck Fotogramétrica Internacional.

\section{HEMEROGRAFÍA}

DDF. Nuestra ciudad, órgano del departamento del Distrito Federal, Ciudad de México, 1930.

DDF. Obras públicas, órgano de la Dirección de Obras Públicas, Ciudad de México, 1930. 
ANPR. Planificación, órgano de la Asociación Nacional para la Planificación de la República, Ciudad de México, 1927-1928.

\section{VISTAS Y PLANOS}

CASTRO, Casimiro. Vista panorámica de la ciudad de México tomada desde un globo. Litografia. Ciudad de México: Decaen y Debray, 1866. Mapoteca Orozco y Berra (Sagarpa) Colección General D.F.Varilla 02, 1232-CGE-725.

DECAEN, Joseph Antoine; DEBRAY,Victor. Plano general de la Ciudad de México. Ciudad de México: Decaen y Debray, 1866. Mapoteca Orozco y Berra (Sagarpa). Colección Orozco y Berra D.F. Varilla 03, 951-OYB-725.

\section{LIBROS Y PERIODICOS}

AGUAYO, Fernando; ROCA, Lourdes (Org.). Investigación con imágenes. Usos y retos metodológicos. Ciudad de México: Instituto Mora; Consejo Nacional de Ciencia y Tecnología (CONACyT), [inédito].

BESSE, Jean-Marc. Geografías aéreas. In: McLEAN, Alex S. La fotografía del territorio. Barcelona: Gustavo Gili, 2003. p. 336-363.

BERMAN, Marshall. Todo lo sólido se desvanece en el aire. La experiencia de la modernidad. Ciudad de México: Siglo XXI, 2000.

CHOMBART DE LAUWE, Paul. La fotografía aérea. Barcelona: Omega, 1956.

DE GARAY, Graciela et al. El arte de hacer ciudad. Ciudad de México: Instituto Mora; Conacyt, 2001.

ECHEVERRÍA, Bolívar. La modernidad de lo barroco (1998). México: Era, 2005.

ETHINGTON, Philip. Los Angeles and the problem of urban historical knowledge. The American Historical Review, Chicago, v. 105, n. 5, Dec. 2000 (Exclusive $e$-AHR multimedia article). Disponible en: <www.historycooperative.org $>$.

FERNÁNDEZ CHRISTLIEB, Federico. Ciudad de México. Barcelona:Alertes, 2000a.

Europa y el urbanismo neoclásico en la Ciudad de México. Antecedentes y esplendores. Ciudad de México: Instituto de Geografía de la UNAM; Plaza y Valdés, 2000b.

GERVAIS, Thierry. Un basculement du regard. Études Photographiques, Paris, n. 9, mai 2001 (EHESS).

GUÁRDIA, Manel. Barcelona: memoria desde el cielo. Barcelona:Ayuntamiento de Barcelona, Generalitat de Catalunya, Departament de Cultura; Lunwerg, 2002.

KATZMAN, Israel. Arquitectura del siglo XIX en México. México:Trillas, 1993.

KRAUSS, Rosalind. Lo fotográfico. Por una teoría de los desplazamientos. Barcelona: Gustavo Gili, 2002.

LEFEBVRE, Henri. Espacio y política. El derecho a la ciudad. Barcelona: Península, 1976.

. El derecho a la ciudad (1968). Barcelona: Península, 1978.

LÓPEZ RANGEL, Rafael. Carlos Contreras en la historia de la planificación urbana. In: SÁNCHEZ RUIZ, Gerardo G. (Org.). Planificación y urbanismo visionarios de Carlos Contreras: escritos de 1925 a 1938.Azcapotzalco: Universidad Autónoma Metropolitana; San Luis Potosí: Universidad Au- 
tónoma de San Luis Potosí; Ciudad de México: Universidad Nacional Autónoma de México, 2003. p. 25-34 (Raíces, 2; Documentos para la Historia de la Arquitectura Mexicana).

OSORIO, Fernando; PLIEGO, Nareni. Captura de la imagen: testimonio impreso. In: et al. México: memoria desde el aire, 1932-1969. México: Fundación ICA; Barcelona: Lunwerg, 2007. p. 25-30.

RIBERA CARBÓ, Eulalia (Org.). Trazos, usos y arquitectura. La estructura de las ciudades mexicanas en el siglo XIX: Ciudad de México: Instituto de Geografía de la Unam, 2004.

ROCA, Lourdes. La imagen como fuente: una construcción de la investigación social. Razón y palabra, Monterrey, México n. 37, 2004. Disponible en <www.razonypalabra.org>.

SANTOS, Milton. Por una geografía nueva. Madrid:Ariel,1990.

.El presente como espacio. Ciudad de México: Unam, 2002.

SCHERER, Joanna C.The Photographic Document: Photographs as Primary Data in Anthropological Enquiry. In: EDWARDS, Elizabeth (Org.), Antbropology and photography, 1860-1926. Londres: Yale University Press; The Royal Anthropological Institute, 1992. p. 32-41.

SONTAG, Susan. Sobre la fotografía. Barcelona: Edhasa, 1996. . Ante el dolor de los demás. México:Alfaguara, 2004.

OTRAS FUENTES

FUNDACIÓN ICA. Codifica - Colección Digital de la Fundación ICA. Disponible en <www.codifica.org.mx>. 